PATRÍCIA SANAE DE SOUZA LOPES

\title{
ESTIMULAÇÃO DO CÓRTEX MOTOR E ANTINOCICEPÇÃO: ENVOLVIMENTO DA VIA DE ANALGESIA SEROTONÉRGICA DESCENDENTE
}

Dissertação apresentada ao Programa de PósGraduação em Fisiologia Humana do Instituto de Ciências Biomédicas da Universidade de São Paulo, para obtenção do Título de Mestre em Ciências. 


\section{ESTIMULAÇÃO DO CÓRTEX MOTOR E ANTINOCICEPÇÃO: ENVOLVIMENTO DA VIA DE ANALGESIA SEROTONÉRGICA DESCENDENTE}

Dissertação apresentada ao Programa de PósGraduação em Fisiologia Humana do Instituto de Ciências Biomédicas da Universidade de São Paulo, para obtenção do Título de Mestre em Ciências.

Área de concentração: Fisiologia Humana

Orientador: Dr. Luiz Roberto G. Britto

Versão corrigida. A versão original eletrônica encontra-se disponível tanto na Biblioteca do ICB quanto na Biblioteca Digital de Teses e Dissertações da USP (BDTD). 
DADOS DE CATALOGAÇÃO NA PUBLICAÇÃO (CIP)

Serviço de Biblioteca e Informação Biomédica do

Instituto de Ciências Biomédicas da Universidade de São Paulo

reprodução não autorizada pelo autor

Lopes, Patrícia Sanae de Souza.

Estimulação do córtex motor e antinocicepção: envolvimento da via de analgesia serotonérgica descendente / Patrícia Sanae de Souza Lopes. -- São Paulo, 2013.

Orientador: Prof. Dr. Luiz Roberto G. Britto.

Dissertação (Mestrado) - Universidade de São Paulo. Instituto de Ciências Biomédicas. Departamento de Fisiologia e Biofísica. Área de concentração: Fisiologia Humana. Linha de pesquisa: Estimulação cortical/ Dor.

Versão do título para o inglês: Motor cortex stimulation and antinociception: involvement of descending serotonergic pain pathway.

1. Estimulação do córtex motor 2. Via de analgesia descendente 3. Serotonina 4. Núcleo dorsal da rafe 5. Núcleo magno da rafe 6. Coluna posterior da medula espinhal I. Britto, Prof. Dr. Luiz Roberto G. II. Universidade de São Paulo. Instituto de Ciências Biomédicas. Programa de Pós-Graduação em Fisiologia Humana III. Título. 
Título da Dissertação: $\quad$ Estimulação do córtex motor e antinocicepção: envolvimento da via de analgesia serotonérgica descendente.

Orientador(a): $\quad$ Prof. Dr. Luiz Roberto G. Britto.

A Comissão Julgadora dos trabalhos de Defesa da Dissertação de Mestrado, em sessão pública realizada a considerou
( ) Aprovado(a)
( ) Reprovado(a)

Examinador(a): Assinatura:

Nome:

Instituição:

Examinador(a): Assinatura:

Nome:

Instituição:

Presidente: Assinatura:

Nome:

Instituição: 


\section{Certificado}

Certificamos que o protocolo registrado sob $n^{\circ} \mathbf{0 5 5}$ nas fls. $\mathbf{1 0 3}$ do livro 02 para uso de animais em experimentação, sob a responsabilidade do Prof(a) $\operatorname{Dr}(a))$ Luiz Roberto Giorgetti de Britto, Coordenador(a) da Linha de pesquisa "Estimulação do córtex motor e antinocicepção descendente: análise da circuitaria neuronal na substância cinzenta periaquedutal" do qual participam o(s) alunos Patrícia Sanae de Souza Lopes e a pesquisadora Rosana de Lima Pagano, está de acordo com os Princípios Éticos de Experimentação Animal adotado pela Sociedade Brasileira de Ciência de Animais de Laboratório (SBCAL) e foi aprovado pela COMISSÃO DE ÉTICA NO USO DE ANIMAIS (CEUA) em 15.07.2011, com validade de 3 anos.

São Paulo, 18 de julho de 2011.
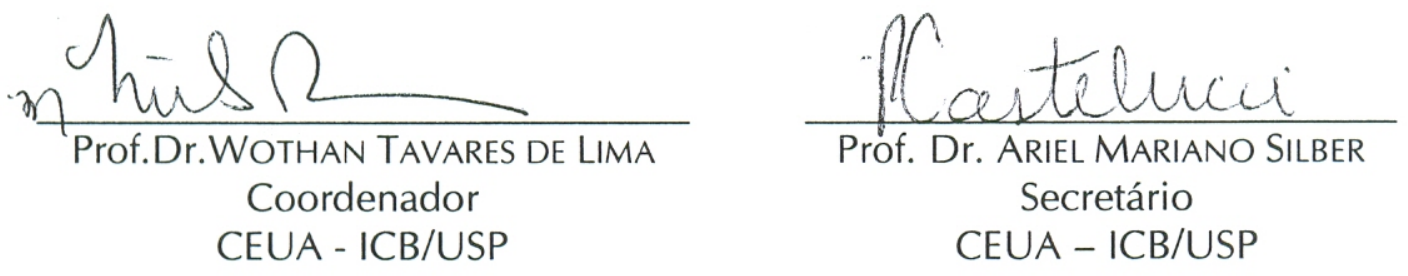


\section{COMISSÃO DE ÉTICA NO USO DE ANIMAIS - CEUA \\ HOSPITAL SÍRIO-LIBANÊS}

REGISTRO CEUA: CEUA2011/13

COORDENADOR: Dra. Rosana de Lima Pagano

TÍTULO DO PROJETO: Estimulação do córtex motor e antinocicepção

descendente: análise da circuitaria neuronal da substância cinzenta

periaquedutal.

Prezado Coordenador,

A Comissão de Ética no Uso de Animais do Instituto de Ensino de Pesquisa do Hospital Sírio-Libanês analisou e APROVOU COM PEQUENAS MODIFICACÕES em 09 de maio de 2011 a realização do projeto de pesquisa.

INFORMACÕES IMPORTANTES:

Comunicar alterações no projeto.

São Paulo, 09 de maio de 2011.

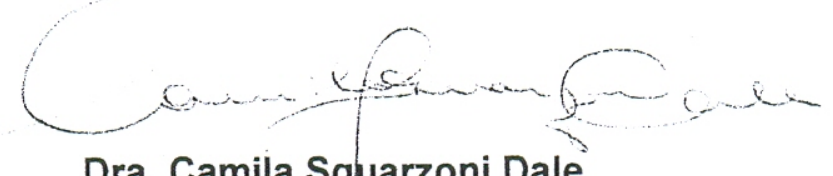

Dra. Camila Squarzoni Dale

Vice Presidente da Comissão de Ética no Uso de Animais - CEUA

Hospital Sírio-Libanês 
Àqueles que esperam na ciência um bálsamo para a sua dor. 


\section{AGRADECIMENTOS}

Agradeço, primeiramente, a Deus, criador e doador de todo conhecimento e sabedoria.

À minha família, que em tudo me apoiou todo esse tempo.

Ao Profo ${ }^{\circ}$. Luiz Britto, que me recebeu e me inseriu no mundo acadêmico.

À Prof ${ }^{a}$ Rosana Pagano, que pacientemente aceitou a árdua tarefa de me tornar de estudante um pesquisador.

Aos parceiros de laboratório, pela amizade.

A todos do ICB/USP e do IEP/HSL, que direta ou indiretamente cooperaram para a realização deste trabalho.

À FAPESP e à CAPES pelo apoio financeiro. 
“Todos são capazes de dominar a dor, exceto quem a sente."

William Shakespeare 


\section{RESUMO}

LOPES, P. S. S. Estimulação do córtex motor e antinocicepção: envolvimento da via de analgesia serotonérgica descendente. 2013. 48 p. Dissertação (Mestrado em Fisiologia Humana) - Instituto de Ciências Biomédicas, Universidade de São Paulo, São Paulo, 2013.

A estimulação epidural do córtex motor (ECM) tem sido eficaz no tratamento de dor crônica refratária, porém os mecanismos envolvidos neste efeito ainda são incertos. Demonstrados previamente que a ECM aumenta o limiar nociceptivo mecânico de ratos, via opióides endógenos, sendo esse efeito decorrente, em parte, da inibição de núcleos talâmicos e da ativação da substância cinzenta periaquedutal mesencefálica (PAG). Sabendo que a ativação da PAG induz a ativação da via de analgesia serotonérgica descendente, fomos investigar o efeito da ECM sobre os principais núcleos dessa via, o núcleo dorsal da rafe (NDR) e o núcleo magno da rafe (NMR), assim como sobre os neurônios da coluna posterior da medula espinhal (CPME), para melhor elucidar os mecanismos envolvidos na analgesia induzida pela ECM. Ratos Wistar foram implantados com eletrodos transdurais sobre o córtex motor primário na área correspondente à pata posterior direita. Após uma semana foram estimulados ( $1 \mathrm{~V}, 60 \mathrm{~Hz}, 210 \mu \mathrm{s})$ por 15 min e ainda sob estimulação foram avaliados no teste de pressão da pata. Ratos naive ou falso-estimulados foram usados como controle. Imediatamente ou $1 \mathrm{~h}$ após a ECM, a imunomarcação para Egr-1 (marcador de ativação neuronal) ou serotonina (5HT) foi avaliada no NDR, no NMR e na CPME. Em adição, foi também avaliada a marcação para substância $P$ (SP) na CPME. A ECM aumentou o limiar nociceptivo em $62 \%$ na pata contralateral a estimulação, quando comparado com os controles. A estimulação cortical não alterou a ativação do NDR, entretanto induziu a ativação do NMR (67\%), quando comparado aos controles. Com relação à $5 \mathrm{HT}$, a ECM induziu um aumento na imunomarcação para $5 \mathrm{HT}$ em $75 \%$ no NDR e em $92 \%$ no NMR. Na medula espinhal, a ECM inibiu os neurônios da CPME (48\%), porém não interferiu com a marcação de fibras SP-positivas. Estes resultados sugerem que a antinocicepção induzida pela ECM é proveniente da ativação do sistema serotonérgico descendente, com consequente inibição dos neurônios nociceptivos espinhais levando ao aumento do limiar nociceptivo. Esses dados reforçam o papel do córtex motor no controle da resposta dolorosa.

Palavras-chave: Estimulação do Córtex Motor. Via de Analgesia Descendente. Serotonina. Núcleo Dorsal da Rafe. Núcleo Magno da Rafe. Coluna Posterior da Medula Espinhal. 


\begin{abstract}
LOPES, P. S. S. Motor cortex stimulation and antinociception: involvement of descending serotonergic pain pathway. 2013. 48 p. Masters thesis (Human Physiology) - Instituto de Ciências Biomédicas, Universidade de São Paulo, São Paulo, 2013.

Motor cortex stimulation (MCS) has been effective in the treatment of refractory chronic pain; however, the mechanisms involved in this effect remain unclear. We previously demonstrate that MCS increases the mechanical nociceptive threshold in rats, via endogenous opioids, being this effect due to thalamic nuclei inhibition and periqueductal gray matter (PAG) activation. Knowing that the PAG activation induces the activation of descending serotonergic pathway, we investigated the MCS effect on the main nuclei of this pathway, the dorsal raphe nucleus (DRN) and the magnus raphe nucleus (MRN), and also on the neurons of the dorsal horn of the spinal cord (DHSC), to better understand the mechanisms involved in MCS-induced analgesia. Male Wistar rats were implanted with transdural electrodes on the motor cortex in the area corresponding to the right hind paw. After one week, the animals were stimulated $(1 \mathrm{~V}, 60 \mathrm{~Hz}, 210 \mu \mathrm{s})$ for $15 \mathrm{~min}$ and still under stimulation they were evaluated by paw pressure test. Naive or sham rats were used as controls. Immediately or $1 \mathrm{~h}$ after MCS, the immunostaining to Egr-1 (neuronal activation marker) or serotonin (5HT) were evaluated in the DRN, MRN and DHSC. Furthermore, it was evaluated the substance $P$ (SP) staining in the DHSC. MCS increased $62 \%$ of nociceptive threshold in the contralateral hindpaw to the stimulation, when compared to control groups. MCS did not modify the NDR activation; however, induced MRN activation (67\%), when compared to controls. Regarding to $5 \mathrm{HT}$, MCS increased $75 \%$ the immunostaining for $5 \mathrm{HT}$ in the NDR and $92 \%$ in the MRN. In the spinal cord, MCS inhibited the DHSC neurons (48\%), however did not change the staining for SP-positive fibers. These results suggest that MCS-induced antinociception is arising to the activation of the descending serotonergic pathway, with subsequent inhibition of the spinal nociceptive neurons, leading to increasing of the nociceptive threshold. These data reinforce the role of the motor cortex in the control of the painful response.
\end{abstract}

Keywords: Motor Cortex Stimulation. Descending Pain Pathway. Serotonin. Dorsal Raphe Nucleus. Magnus Raphe Nucleus. Dorsal Horn of the Spinal Cord. 


\section{LISTA DE ILUSTRAÇÕES}

Figura 1 - Via ascendente de dor

Figura 2 - Principais estruturas envolvidas na modulação nociceptiva.

Figura 3 - Via de analgesia descendente. 21

Figura 4 - Mapa funcional das áreas motoras com a ECM. 25

Figura 5 - Estruturas onde foram feitas as análises imuno-histoquímicas 28

Figura 6 - Efeito da ECM sobre o limiar nociceptivo mecânico 29

Figura 7 - Análise do padrão de ativação neuronal no NDR 30

Figura 8 - Análise da marcação serotonérgica no NDR 31

Figura 9 - Análise do padrão de ativação neuronal no NMR. 32

Figura 10 - Análise da marcação serotonérgica no NMR 33

Figura 11 - Análise do padrão de ativação neuronal na CPME. 34

Figura 12 - Análise do padrão de marcação para SP na CPME. 35 


\section{LISTA DE ABREVIATURAS E SIGLAS}

5HT - 5-hidroxitriptamina (serotonina)

$5 \mathrm{HT}_{1 \mathrm{~A}}$ - receptor de serotonina do tipo $1 \mathrm{~A}$

CGRP - peptídeo relacionado ao gene da calcitonina

CPME - coluna posterior da medula espinhal

ENK - encefalina

GABA - ácido y-aminobutírico

GLU - glutamato

LC - locus ceruleus

$\mathrm{M}-\mathrm{I}$ - córtex motor primário

MOR - receptor opióide do tipo mu

NDR - núcleo dorsal da rafe

NK1 - receptor de neurocinina do tipo 1

NMR - núcleo magno da rafe

NR1 - receptor NMDA da subunidade 1

PAG - substância cinzenta periaquedutal mesencefálica

RVM - bulbo ventromedial rostral

S-I - córtex somatosensorial primário

S-II - córtex somatosensorial secundário

SP - substância P 
1 INTRODUÇÃO E OBJETIVO ............................................................... 14

1.1 Objetivos específicos........................................................................ 14

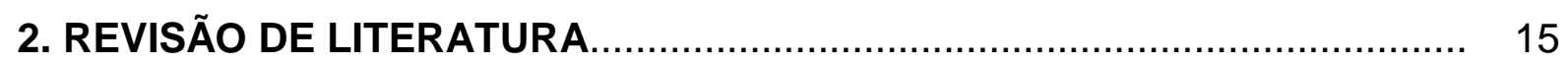

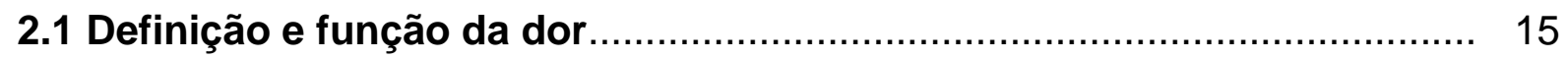

2.2 Geração e transmissão do estímulo doloroso (via aferente nociceptiva) 15

2.3 Modulação do estímulo doloroso (via de analgesia descendente).......... 17

2.4 Estimulação cortical, ativação neuronal e analgesia................................ 22

3 MATERIAL E MÉTODOS.................................................................... 24

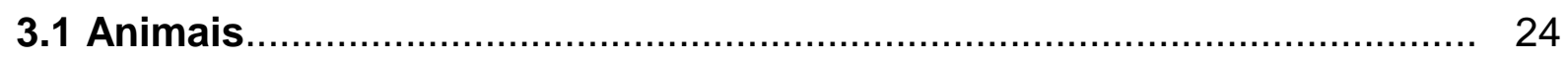

3.2 Implante dos eletrodos transdurais e parâmetros da estimulação

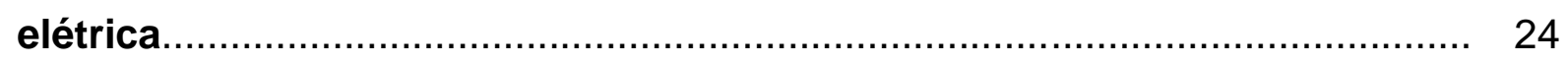

3.3 Avaliação da resposta nociceptiva mecânica (teste de pressão de pata) 26

3.4 Imuno-histoquímica....................................................................... 26

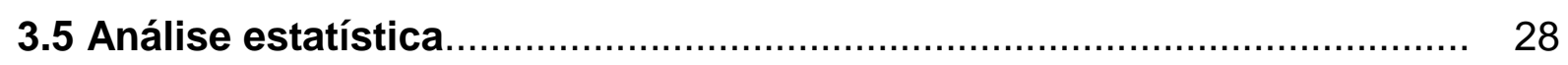

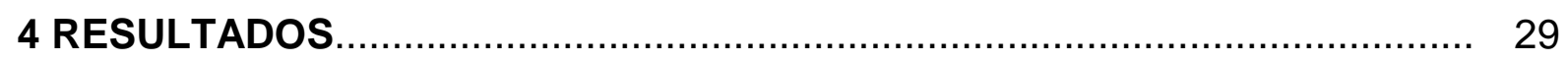

4.1 Efeito da ECM sobre a resposta nociceptiva mecânica........................... 29

4.2 Efeito da ECM sobre ativação neuronal do NDR ................................... 30

4.3 Efeito da ECM sobre a marcação para serotonina no NDR ...................... 31

4.4 Efeito da ECM sobre a ativação neuronal no NMR ……......................... 32

4.5 Efeito da ECM sobre a marcação para serotonina no NMR ..................... 33

4.6 Efeito da ECM sobre a ativação neuronal na CPME............................... 34

4.7 Efeito da ECM sobre a marcação de fibras SP-positivas na CPME......... 35

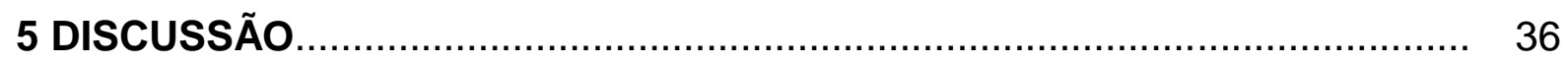

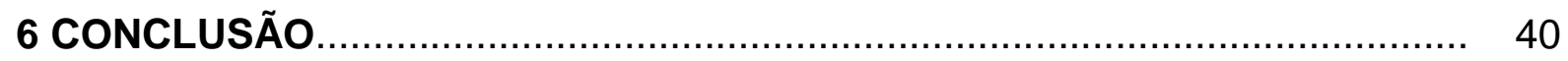

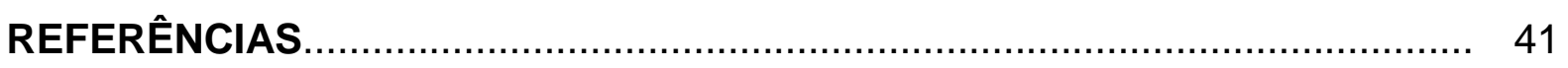




\section{INTRODUÇÃO E OBJETIVO}

Aproximadamente um terço da população mundial sofre de dor crônica ou persistente, tornando-se esta uma das mais frequentes razões para a procura de atendimento médico, trazendo altos gastos em saúde pública, quanto agravos e comorbidades físicas e emocionais aos pacientes (STUCKY et al., 2001). Uma variedade de tratamentos farmacológicos tem sido proposta para controle da dor neuropática, porém, até o momento, nenhum deles responde de maneira satisfatória. Desta maneira, o aprimoramento terapêutico em tais condições dolorosas se faz necessário. Nesse sentido, a estimulação do córtex motor (ECM), uma técnica terapêutica não destrutiva, ajustável e reversível, tem sido aplicada no tratamento de dores centrais complexas ou síndromes periféricas neuropáticas, resistentes à outros tratamentos (FAGUNDES-PEREYRA et al., 2010). Entretanto, a ECM falha em reverter a dor neuropática em aproximadamente um terço dos pacientes (NGUYEN et al., 2000), apontando para uma necessidade de prosseguir com a pesquisa nesse campo. Anteriormente, nosso grupo demonstrou que a ECM ativa a substância cinzenta periaquedutal mesencefália (PAG) (PAGANO et al., 2012). Considerando que a PAG está intimamente ligada a neurônios do núcleo dorsal da rafe (NDR), que junto com o núcleo magno da rafe (NMR) modulam a resposta dolorosa pela via serotonérgica descendente (BAJIC; COMMONS, 2010; BASBAUM; FIELDS, 1984), agindo sobre neurônios nociceptivos espinhais com a finalidade de inibir a transmissão do estimulo nociceptivo (VIISANEN; PERTOVAARA, 2010b), decidimos investigar o efeito da estimulação cortical sobre a ativação dos núcleos serotonérgicos NDR e NMR, envolvidos na via de analgesia descendente, e sobre os neurônios da coluna posterior da medula espinhal (CPME).

\subsection{Objetivos específicos}

1. Avaliar o padrão de ativação neuronal no NDR, NMR e CPME, visto por imunomarcaçao para Egr-1;

2. Avaliar o padrão de imunomarcação para serotonina (5HT) no NDR e NMR;

3. Avaliar o padrão de imunomarcação para substância P (SP) na CPME. 


\section{REVISÃO DE LITERATURA}

\subsection{Definição e função da dor}

Segundo a Associação Internacional para o Estudo da Dor (IASP), a dor é iniciada ou causada por uma lesão primária ou disfunção no sistema nervoso (MERSKEY; BOGDUK, 1994). Entretanto, as definições de dor sofreram grandes modificações por volta das décadas de 50 e 60, sendo que, além dos eventos físicos que abrangem a sensação dolorosa, foram considerados aspectos emocionais e culturais (PIMENTA; KOIZUMI; TEIXEIRA, 2000). Sendo assim, mais do que uma experiência sensorial desagradável (MEYER et al., 2006), ou simplesmente um estímulo nocivo, a dor é uma experiência complexa multidimensional, pois envolve componentes neurais discriminativos, emocionais e cognitivos (XIE; HUO; TANG, 2009), e tem como função nos alertar de qualquer perigo ou lesão iminente, desencadeando respostas defensivas com a finalidade de manter a integridade do organismo (JULIUS; BASBAUM, 2001) e de oferecer segurança e condições para a sua recuperação (PLONER et al., 2006).

\subsection{Geração e transmissão do estímulo doloroso (Via aferente nociceptiva)}

Presentes na pele, vísceras, articulações e ossos, os neurônios com propriedades singulares específicas para a detecção de estímulos nocivos de natureza térmica, química ou mecânica são chamados de nociceptores (JULIUS; BASBAUM, 2001). Essa particular capacidade dos nociceptores se deve à presença de receptores de alto limiar, que são ativados somente frente à estímulos nocivos (JULIUS; BASBAUM, 2001; SCHOLZ; WOOLF, 2002). Em condições de lesão tecidual e/ou inflamação, diversas substâncias são liberadas pelas células do local afetado, como bradicinina, prostaglandina e histamina, que tem a capacidade de ativar esses receptores (JULIUS; BASBAUM, 2001; TAI; ZHU; ZHOU, 2008). Quando ativados, esses receptores geram mudanças no potencial elétrico dos terminais periféricos dos nociceptores, aumentando a entrada de sódio via canais de sódio dependentes de voltagem, ultrapassando o limiar de membrana e por fim, desencadeando potenciais de ação que são conduzidos da periferia à CPME (BINSHTOK et al., 2008). Os nociceptores conduzem o estímulo nociceptivo via 
fibras nervosas de diferentes calibres que são classificadas como $A \delta$, fibras mielinizadas com alta velocidade de condução e de grande calibre e fibras C, fibras amielinizadas, com menor velocidade de condução e de pequeno calibre, sendo que $70 \%$ dos nociceptores possuem fibras do tipos C (DJOURI; LAWSON, 2004; STUCKY et al., 2001).

Ao ser conduzido ao longo da fibra aferente nociceptiva, o estímulo nociceptivo é transmitido aos neurônios de projeção (ou neurônios de segunda ordem) da CPME, e essa sinapse é mediada por diversos neurotransmissores, tais como SP, peptídeo relacionado ao gene da calcitonina (CGRP) e glutamato (TRAFTON et al., 1999; WOOLF; SATER, 2006). A CPME é dividida anatomicamente em lâminas, numeradas de I a VI, de acordo com Rexed (1952), considerando as diferenças no tamanho e densidade dos neurônios (GRAHAM; BRICHTA; CALLISTER, 2007). Nestas lâminas as aferências somatossensoriais provenientes da periferia fazem sinapse com neurônios de projeção e, estes cruzam a linha mediana e ascendem em direção às regiões supraespinhais. A coluna posterior superficial, formada pelas lâminas I e II, recebe grande parte dos impulsos elétricos das fibras A $\delta$ e C (LU, 2008). Uma parte significativa dos neurônios centrais situados na lâmina I da CPME possui receptores NK1, sendo responsivos à SP (MAZARÍO; BASBAUM, 2007).

Os neurônios de projeção conduzem a informação nociceptiva da medula até estruturas do tronco encefálico e diencéfalo por diferentes vias ascendentes, sendo as principais delas a via espinotalâmica, espinomesencefália e espinoreticular (MILLAN, 1999). A via nociceptiva espinotalâmica é a mais proeminente na condução do impulso nociceptivo onde os neurônios de projeção da CPME ascendem para diversos núcleos talâmicos envolvidos com os componentes discriminativos e afetivos da dor (JESSEL, 1991). No tálamo ocorre a recepção, integração e transferência da informação nociceptiva para o córtex cerebral, onde a informação pode ser somatotopicamente organizada e processada (DOSTROVSKY; CRAIG, 2006). Dentre as principais regiões corticais envolvidas no processamento da resposta nociceptiva estão os córtices sensorial primário (S-I), secundário (S-II), motor (BROMM; TREEDE, 1987; SCHNITZLER; PLONER, 2000), cingulado anterior e insular (BUSHNELL et al., 1999) (Figura 1). 
Figura 1 - Vias ascendentes de dor.
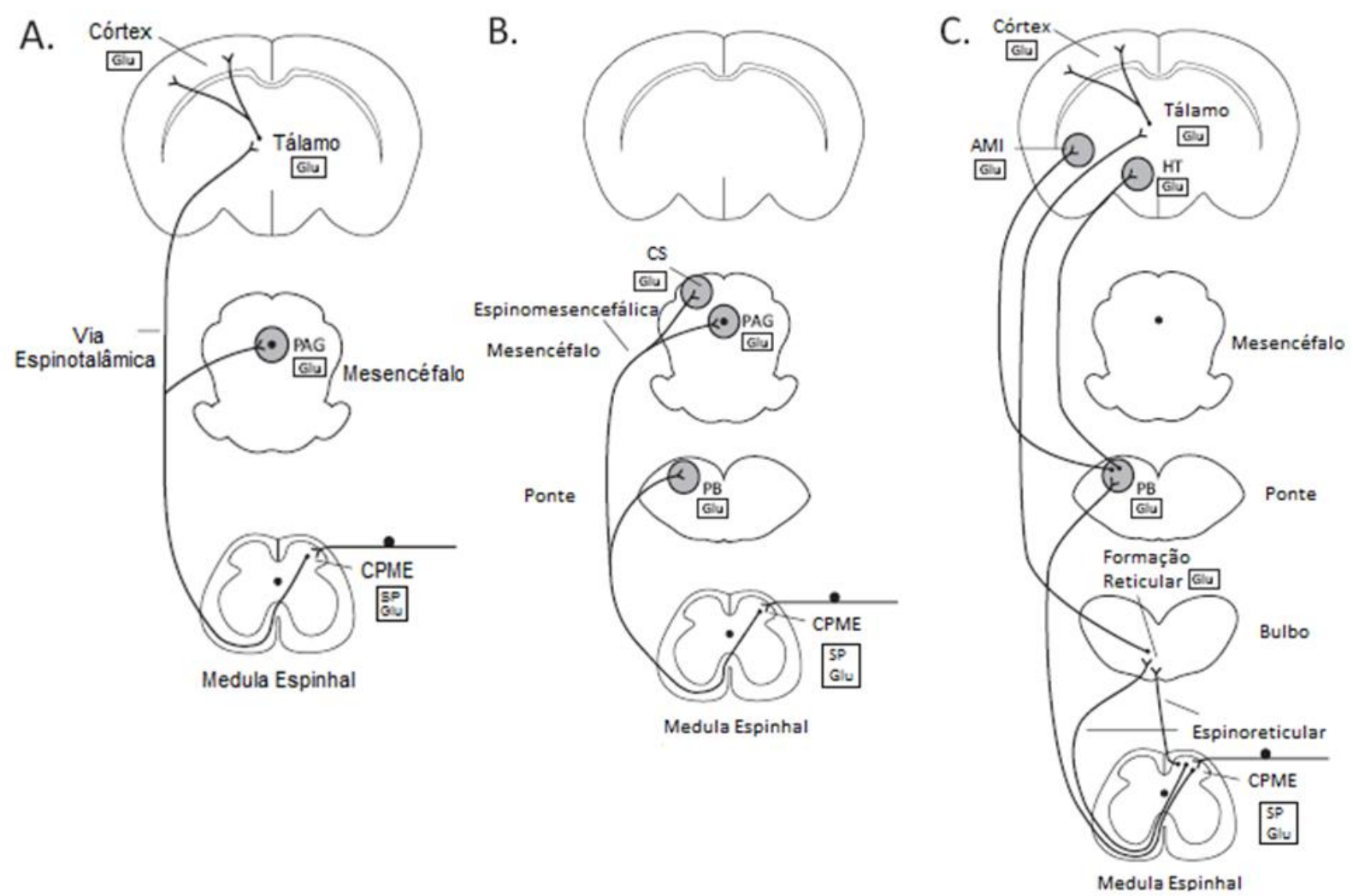

Imagem das principais vias que compreendem a via ascendente de dor. A. Via espinotalâmica. B. Via espinomesencefálica. C. Via espinoreticular. O estímulo nociceptivo é transmitido para o neurônio de projeção via substância $P$ (SP) e glutamato (Glu) e ascende a medula espinhal em direção ao tronco encefálico, ao tálamo e ao córtex, ativando diferentes estruturas. AMI: amídala. HT: hipotálamo. PB: núcleo parabraquial. PAG: substância cinzenta periaquedutal mesencefálica. CS: colículo superior.

Fonte: (VIISANEN-KUOPILA, 2012).

\subsection{Modulação do estímulo doloroso (Via de analgesia descendente)}

O sistema nervoso possui circuitos modulatórios que regulam a percepção da dor e o sítio final desta modulação é a medula espinhal, onde conexões entre vias envolvidas ou não com a analgesia podem controlar a transmissão da informação nociceptiva que será enviada para centros supraespinhais (BASBAUM; FIELDS, 1984; FIELDS; BASBAUM; HEINRICHER, 2006). O conceito de mecanismo inibitório de dor que perdura até os dias de hoje é a teoria da comporta, elaborado por Melzack e Wall (1965), que consiste na inibição da transmissão do impulso nociceptivo por interneurônios inibitórios, presentes na lâmina II da CPME. Posteriormente, foi demonstrado que estruturas encefálicas também exercem 
atividade inibitória ou facilitatória sobre as células da CPME (FIELDS; BASBAUM; HEINRICHER, 2006; MILLAN, 2002). A demonstração do envolvimento de estruturas encefálicas como amígdala, hipotálamo, PAG e tálamo na analgesia contribuiu significativamente para confirmar a existência e despertar o interesse sobre o mecanismo descendente de supressão da dor (KUHAR; PERT; SNYDER, 1973).

Dentre as principais estruturas modulatórias nociceptivas estão a PAG, 0 hipotálamo, as estruturas do sistema límbico como amígdala, córtex cingulado anterior e ínsula anterior, o locus ceruleus (LC) e o bulbo ventromedial rostral (RVM), onde se localiza a formação reticular adjacente e o núcleo magno da rafe (NMR). Todas estas estruturas possuem inervações diretas para a CPME (ALMEIDA; ROINZENBLATT; TUFIK, 2004; BRAZ; ENQUIST; BASBAUM, 2009; BASBAUM; HEINRICHER, 2006; MASON, 2001; MILLAN, 1999; ROSENFELD, 1994; SANDKUHLER, 1996). O núcleo dorsal da rafe (NDR) tem sido incluído neste grupo por agir relevantemente na modulação nociceptiva (WANG; NAKAI, 1994), modulação esta que é provavelmente mediada através da sua conexão direta com o NMR ou indireta com a CPME ou com o tálamo (PALAZZO et al., 2006) (Figura 2).

A PAG é citoarquitetonica e quimicamente heterogênia e possui quatro subdivisões, nomeadas de dorsomedial, dorsolateral, lateral e ventrolateral, que diferem na sua contribuição na modulação da dor e no controle autonômico (BANDLER; SHIPLEY, 1994). Neurônios das subdivisões da coluna lateral estão mais envolvidos com a informação aferente relacionada a insultos cutâneos, enquanto a coluna ventrolateral está relacionada com dor visceral e somática profunda (CLEMENT et al., 2000; KEAY; BANDLER, 1993; KEAY et al., 1994;). A PAG recebe aferências de diferentes origens, tais como hipotálamo, córtex frontal e insular, amígdala, núcleo parafascicular do tálamo, LC, formação reticular e CPME (AGGLETON, 1992; BEITZ, 1982; HERBERT; SAPER, 1992). A PAG possui muitos neurônios que contém encefalina, SP e ácido $\mathrm{Y}$-aminobutírico (GABA), sendo que alguns destes neurônios projetam-se diretamente para o RVM (SANDKUHLER, 1996; VANEGAS; SCHAIBLE, 2004).

O NDR está intimamente ligado à PAG por sua localização anatômica, mas difere muito desta região por suas características citoarquitetônicas e fisiológicas (WANG; NAKAI, 1994). O NDR contém o maior grupo de neurônios serotonérgicos no encéfalo de mamíferos (DAHLSTROM; FUXE, 1964). A coluna ventrolateral da 
PAG (vIPAG), uma das colunas mais efetivas no controle da analgesia (BASBAUM; FIELDS, 1984), é a região onde parte dos neurônios serotonérgicos do NDR estão localizados (BAJIC; COMMONS, 2010). Apesar da sua função antinociceptiva, o NDR contém populações de neurônios pró-nociceptivos, sugerindo seu papel tanto na inibição como na facilitação nociceptiva (WANG; NAKAI, 1994). Terminais serotonérgicos localizados na CPME são de origem supraespinhal (STAMFORD, 1995) sendo parte desses terminais oriundos do NDR (WANG; NAKAI, 1994), porém grande parte da modulação nociceptiva na CPME é proveniente do NMR (OLIVERAS et al., 1977).

Figura 2 - Principais estruturas envolvidas na modulação nociceptiva.

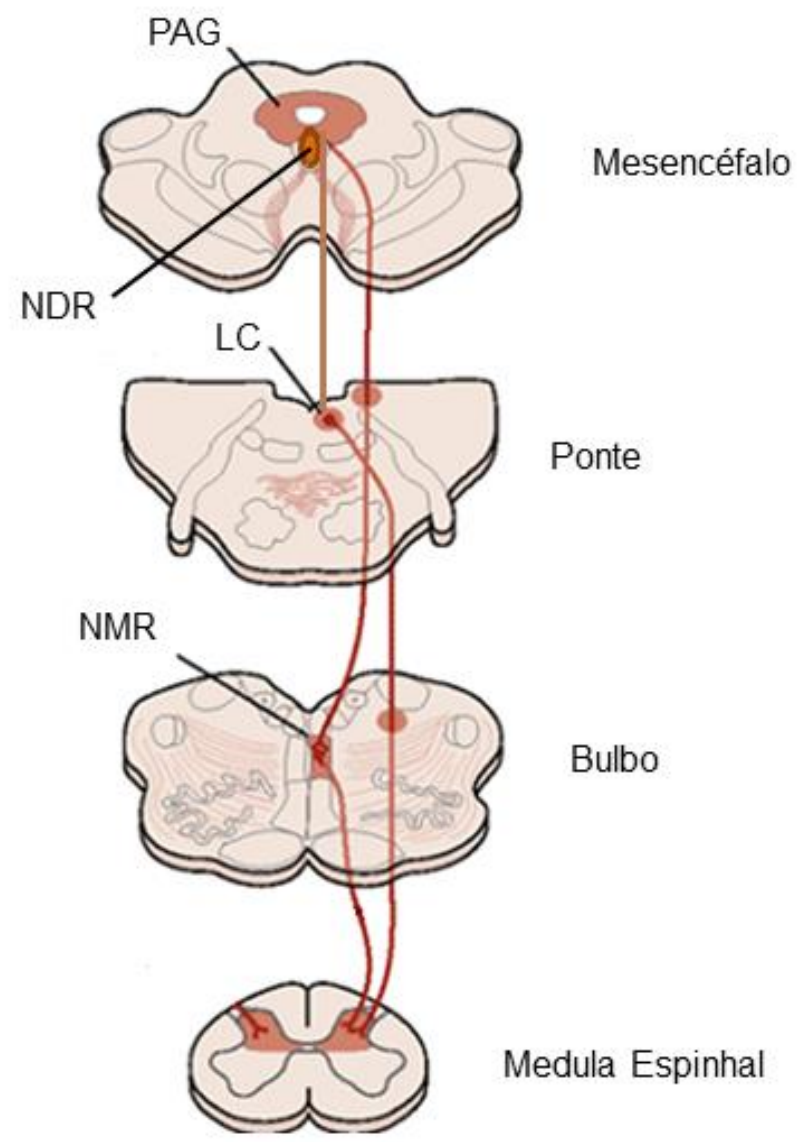

Imagem das principais estruturas que compreendem a via de analgesia descendente. PAG substância cinzenta periaquedutal mesencefálica. NDR - núcleo dorsal da rafe. LC - locus ceruleus e NMR - núcleo magno da rafe (Modificado de KANDEL; SCHWARTZ; JESSELL, 2000). 
A conexão entre a PAG e o RVM é crítica para a modulação da dor (BEHBEHANI; FIELDS, 1979; URBAN; SMITH, 1994). Dentre os núcleos do RVM implicados no mecanismo de supressão da dor destacam-se o NMR, rico em neurônios serotonérgicos, e os neurônios da formação reticular adjacente que recebem projeções oriundas da PAG, do hipotálamo posterior e do LC, rico em neurônios noradrenérgicos (FIELDS; BASBAUM, HEINRICHER, 2006; MASON, 2001; ROSENFELD, 1994; SANDKUHLER, 1996;). Neurônios da NMR projetam-se diretamente para a medula espinhal, onde inibem a transmissão nociceptiva (BASBAUM; FIELDS, 1984; FIELDS; HEINRICHER; MASON, 1991). As lâminas I, II e III da CPME possuem massiva expressão do receptor inibitório do subtipo $5 \mathrm{HT}_{1 \mathrm{~A}}$ (CROUL et al., 1998). Da mesma forma, a conexão PAG - LC coopera para a inibição nociceptiva, onde a ativação de neurônios noradrenérgicos do LC via SP, dopamina e/ou glutamato resulta na liberação de noradrenalina na CPME (MILLAN, 2002). Os axônios eferentes das vias serotonérgicas e/ou noradrenérgicas consolidam a inibição nociceptiva descendente através de sinapses com os neurônios de projeção, via receptores $5 \mathrm{HT}_{1 \mathrm{~A}}$ e a2-adrenérgico, respectivamente, e com os interneurônios inibitórios GABAérgicos, glicinérgicos e encefalinérgicos da CPME (JESSEL, 1991; SUZUKI et al., 2004), inibindo a liberação de neurotransmissores nociceptivos excitatórios, como glutamato, SP e CGRP pelos neurônios de projeção (CURTIS; HOSLI; JOHNSON, 1967; MALCANGIO; BOWERY, 1996) (Figura 3). 
Figura 3 - Via de analgesia descendente.

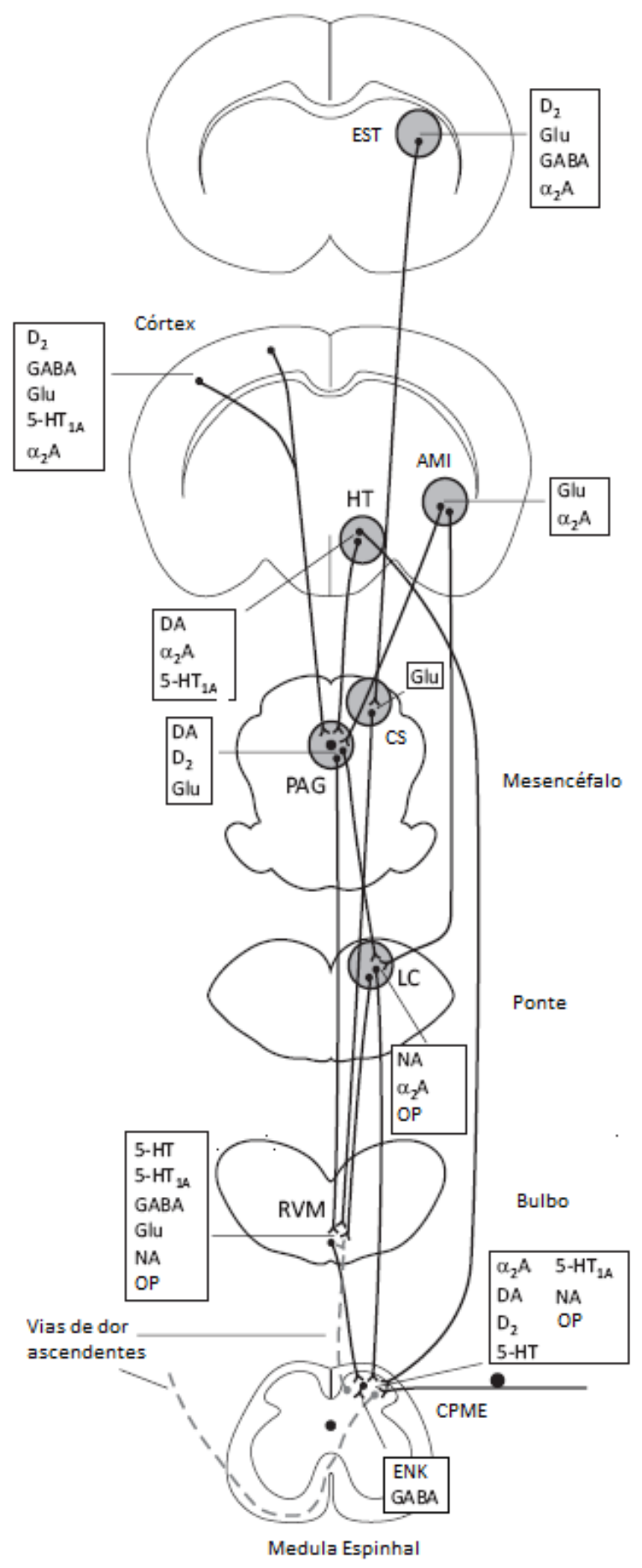

Imagem da via de analgesia descendente. Diferentes estruturas supraespinhais participam da ativação dessa via pela ação da dopamina (DA), glutamato (Glu), GABA, serotonina $(5 \mathrm{HT})$ e noradrenalina (NA). Ao chegar à CPME, o estímulo nociceptivo é inibido por $5 \mathrm{HT}$, NA, DA e opióides (OP) liberados pela via descendente e por encefalina (ENK) e GABA liberados pelos interneurônios inibitórios locais. EST: estriado. AMI: amígdala. HT: hipotálamo. SC: colículo superior. PAG: substância cinzenta periaquedutal mesencefálica. LC: locus ceruleus. RVM: bulbo ventromedial rostral. $5 \mathrm{HT}_{1 \mathrm{~A}}$ : receptor para $5 \mathrm{HT}$ tipo $1 \mathrm{~A}$. $\mathrm{a}_{2} \mathrm{~A}$ : receptor para noradrenalina do tipo $\alpha_{2}$. $D_{2}$ : receptor para DA do tipo 2 .

Fonte: (VIISANEN-KUOPILA, 2012). 


\subsection{Estimulação cortical, ativação neuronal e analgesia}

A utilização de estimulação elétrica cortical para o tratamento da dor foi inicialmente reportada por Tsubokawa e colaboradores (1990), que se baseavam na hipótese de que o impulso elétrico poderia ativar neurônios sensoriais presentes no local da estimulação, consequentemente levando a inibição de neurônios nociceptivos situados no córtex cerebral (TSUBOKAWA et al., 1991, 1993). Desde então, a estimulação cortical ganhou atenção por sua eficácia no tratamento de várias síndromes dolorosas refratárias (CANAVERO; BONICALZI, 2002; GARCIALARREA et al., 1999; NGUYEN et al., 1999; 2000; NUTI et al., 2005; RASCHE et al., 2006). Foi sugerido que a estimulação cortical é capaz de ativar o sistema antinociceptivo descendente (JASMIN et al., 2003; OHARA; VIT; JASMIN, 2005), entretanto as vias e mecanismos de ação eram desconhecidas.

Posteriormente, utilizando modelos experimentais em ratos, foi observado por eletrofisiologia, que a estimulação elétrica subdural do córtex motor induz a inibição da atividade de neurônios da CPME (SENAPATI; HUNTINGTON; PENG, 2005a), além da reversão da dor neuropática de origem central (RUSINA et al., 2005) e periférica (VACULIN et al., 2008). O efeito analgésico observado em ratos com dor neuropática foi mediado pela ativação dos neurônios do LC (VIISANEN; PERTOVAARA, 2010a), do RVM e da via serotonérgica descendente, via receptores $5 \mathrm{HT}_{1 \mathrm{~A}}$ espinhais (VIISANEN; PERTOVAARA, 2010b). Entretanto, a via noradrenérgica parece não ser crítica nesta via, ao contrário da via serotonérgica, que exibe modulação relevantemente potente (VIISANEN; PERTOVAARA, 2010a, b). $\mathrm{Na}$ tentativa de mimetizar o protocolo clínico menos invasivo utilizado em humanos, foi demonstrado pelo nosso grupo que a estimulação elétrica transdural do córtex motor, na área somatotópica correspondente a pata posterior direita, aumenta o limiar nociceptivo mecânico de ratos naive, na pata contralateral a estimulação, sem interferir com a reposta motora dos animais, sendo esse efeito devido a participação de opióides (FONOFF et al., 2009a).

A expressão dos proto-oncogenes, egr-1 (krox-24, zif268 ou zenk), c-fos e cjun, têm sido extensivamente avaliada no sistema nervoso para o mapeamento de ativação das vias neuronais (BECKMANN; WILCE, 1997; HERRERA; ROBERTSON, 1996; MORGAN; CURRAN, 1989; SAGAR; SHARP; CURRAN, 1988). Nesse sentido, foi demonstrado pelo nosso grupo, tanto por eletrofisiologia como por 
marcação para Egr-1, que a estimulação cortical induz a inibição de núcleos talâmicos e a desinibição da via analgésica descendente na PAG (PAGANO et al., 2012). Considerando que a estimulação cortical ativa a PAG (PAGANO et al., 2012) e que essa resposta é modulada principalmente pela via serotonérgica descendente (VIISANEN; PERTOVAARA, 2010b), decidimos investigar o efeito da estimulação cortical sobre a ativação dos núcleos serotonérgicos NDR e NMR, envolvidos na via analgésica descendente oriunda da PAG, e consequentemente sua modulação sobre a CPME com o intuito de melhor delinear o papel da ECM na modulação da resposta nociceptiva. 


\section{MATERIAL E MÉTODOS}

\subsection{Animais}

Foram utilizados ratos Wistar com 2 meses de idade (180-220 g), fornecidos pela Anilab Animais de Laboratório Criação e Comércio LTDA-EPP. Os animais foram mantidos em sala apropriada no Instituto de Ensino e Pesquisa do Hospital Sírio-Libanês (IEP/HSL), com ciclo claro e escuro (12/12 h), temperatura constante $\left(22 \pm 2{ }^{\circ} \mathrm{C}\right)$ e acesso livre à água e ração por um período mínimo de dois dias antes da sua utilização. Os animais foram manipulados considerando os princípios e o guia de uso de animais de laboratório envolvendo dor e nocicepção (ZIMMERMANN, 1983), sendo o projeto aprovado pela Comissão de Ética para o Uso de Animais (CEUA) do Hospital Sírio Libanês (CEUA 2011/13) e pelo Instituto de Ciências Biomédicas da Universidade de São Paulo (nº 055 nas fls. 103 do livro 02, 2011).

\subsection{Implante dos eletrodos transdurais e parâmetros da estimulação elétrica}

Os animais foram submetidos à anestesia geral quetamina (cloridrato de dextrocetamina $50 \mathrm{mg} / \mathrm{ml}$, Cristália) e xilazina (cloridrato de xilazina $2 \%$, Syntec), 1:1, $100 \mu \mathrm{L} / 100 \mathrm{~g}$ de peso corpóreo, via i.m., associada à anestesia local lidocaína (cloridrato de lidocaína $2 \%$, Cristália), $100 \mu \mathrm{L} /$ animal/ escalpo, via s.c. e fixados em um aparelho de estereotaxia. Quando necessário, doses complementares de quetamina foram administradas. Um par de eletrodos de aço inoxidável (diâmetro de $0,8 \mathrm{~mm}$ ) foi inserido em pequenas trepanações realizadas sobre a área do córtex motor primário correspondente a pata posterior direita, de acordo com mapa funcional do córtex motor de rato construído pelo nosso grupo de pesquisa (FONOFF et al., 2009b) (Figura 3). Um par de parafusos de fixação foi implantado 4 a $6 \mathrm{~mm}$ próximo ao local da estimulação. Os eletrodos foram fixados ao crânio utilizando resina acrílica polimerizante. Os prolongamentos dos eletrodos foram inseridos em um soquete, para a posterior conexão com os cabos do estimulador, o qual também foi fixado com polímero acrílico, funcionando como isolante elétrico dos contatos do soquete. Durante 3 dias consecutivos, os animais receberam antiinflamatório (cetoprofeno $100 \mathrm{mg}$ - 0,05 ml/ kg, via s.c.). Uma semana após a implantação dos eletrodos os animais foram submetidos à estimulação elétrica 
transdural do córtex motor, de acordo com estudo anterior realizado pelo nosso grupo (FONOFF et al., 2009a). Cabe ressaltar que nesse trabalho os parâmetros ideais da estimulação cortical foram padronizados para induzir o aumento do limiar nociceptivo na pata contralateral ao córtex estimulado, sem interferir com o limiar nociceptivo da pata ipsolateral à estimulação e sem alterar a resposta motora dos animais avaliados no teste do campo aberto (FONOFF et al., 2009a). As sessões de estimulação foram aplicadas por 15 minutos ( $1 \mathrm{~V}$, corrente entre 0,9 e $1 \mathrm{~mA} ; 60 \mathrm{~Hz}$; $210 \mu$ s de duração do pulso), utilizando o estimulador elétrico Medtronic ${ }^{\circledR}$. Ao final desse período, porém ainda sob estimulação, os animais foram reavaliados no teste nociceptivo. Como animais controles, foram utilizados ratos sem nenhuma intervenção cirúrgica (naive) e ratos submetidos à implantação dos eletrodos, sem estimulação cortical (falso estimulado - sham).

\section{Figura 4 - Mapa funcional das áreas motoras com a ECM.}

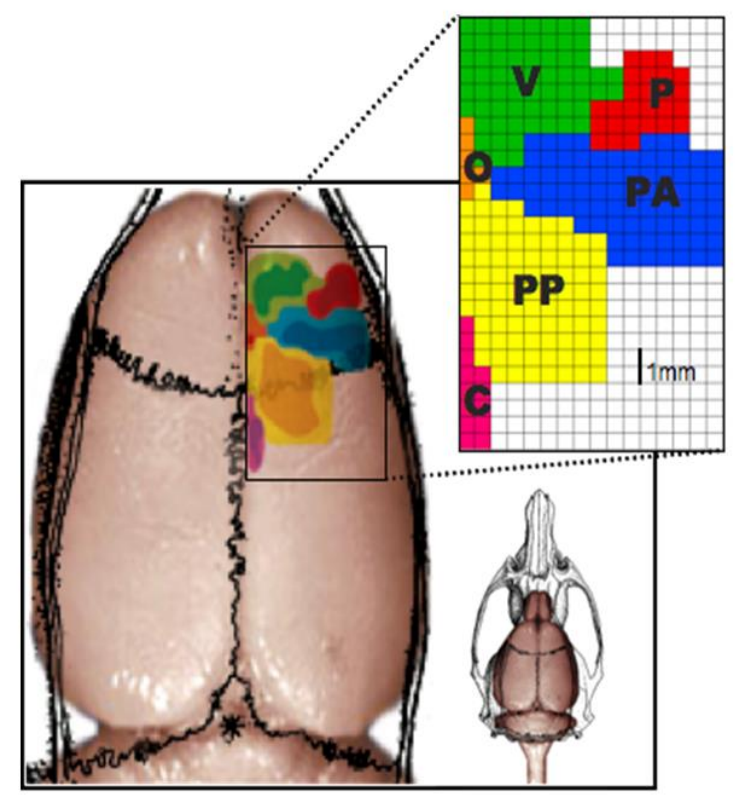

Imagem ilustrando as áreas corticais somatotópicas do rato. V-vibrissas. P-músculos do pescoço, O-músculos oculares, C-cauda, PA-pata anterior e PP-pata posterior, sendo esta última área a região cortical escolhida para a aplicação da estimulação elétrica.

Fonte: (FONOFF at al., 2009b). 


\subsection{Avaliação da resposta nociceptiva mecânica (Teste de pressão da pata)}

A estimulação nociceptiva mecânica foi avaliada utilizando o teste de pressão de pata (Analgesímetro, Insight ${ }^{\circledR}$ ) (RANDALL; SELITTO, 1957). Neste teste, uma força em gramas de intensidade crescente é continuamente aplicada sobre o dorso das patas posteriores do animal. A resposta nociceptiva do animal é dada pela reação de retirada da pata pressionada. O limiar nociceptivo é expresso em gramas de força necessária para a indução da reação de retirada. $O$ teste nociceptivo foi realizado antes da cirurgia de implante dos eletrodos (medida inicial - MI) e duas vezes após uma semana do implante (medida final 1- MF1 e MF2, com intervalo de 15 minutos entre elas). Os resultados foram analisados através da comparação das medidas iniciais e finais e entre os diferentes grupos. Com o intuito de minimizar o estresse dos animais frente ao teste utilizado, os animais foram adaptados um dia antes dos testes no aparelho.

\subsection{Imuno-histoquímica}

Imediatamente após os testes nociceptivos (para o ensaio com 5HT e SP) ou $1 \mathrm{~h}$ após os testes (para o ensaio com Egr-1), os animais foram anestesiados com quetamina (cloridrato de dextrocetamina $50 \mathrm{mg} / \mathrm{ml}$, Cristália) e xilazina (cloridrato de xilazina 2\%, Syntec), 1:1, $250 \mu \mathrm{L} / 100 \mathrm{~g}$ de peso corpóreo, via i.p. e submetidos à perfusão transcardíaca, com solução salina $0.9 \%$, seguida de solução de formaldeído 4\% (PFA) dissolvido em tampão fosfato 0,1 M (PB, pH 7,4). Cabe salientar que, para a análise da marcação para Egr-1, os animais foram perfundidos $1 \mathrm{~h}$ após último teste nociceptivo uma vez que o pico de expressão proteica dos proto-oncogenes ocorre $1 \mathrm{~h}$ após o estímulo nociceptivo e decai entre 3 e $4 \mathrm{hs}$ (HERDEGEN; LEAH, 1998). Após a perfusão, os encéfalos e as medulas espinhais foram coletados e armazenados em PFA por $4 \mathrm{~h}$ e após este período, o material foi transferido para uma solução de sacarose a 30\% em PB. Após 48 hs, os tecidos foram cortados em uma espessura de $30 \mu \mathrm{m}$ em micrótomo deslizante de congelamento (Leica, EUA). As amostras dos cortes histológicos foram coletados em placa de cultivo de 6 unidades contendo solução anti-freenzing (PB 0.05M, sacarose e etilenoglicol) e mantidos a $-20^{\circ} \mathrm{C}$. No momento do ensaio, os cortes foram mantidos sob agitação constante a temperatura ambiente, e submetidos às 
seguintes etapas: a) 3 lavagens de 10 min cada, em PB; b) incubação por 12-16 h com o anticorpo primário específico para Egr-1 (1:1000, Santa Cruz Biotechnology, Inc. CA, US), 5HT (1:1000, Millipore Corporation, USA) e SP (1:1000, Millipore Corporation, USA), diluído em $0,3 \%$ de triton $\mathrm{X}-100$, contendo $50 \mu \mathrm{L}$ de soro de burro normal; c) 3 lavagens com PB; d) incubação por 2 hs com anticorpo secundário biotinilado (1:200, Jackson ImmunoResearch Laboratories, Inc. West Grove, PA, USA) diluído em triton X-100; e) 3 lavagens com PB; g) incubação por 2 hs com complexo avidina-biotina-peroxidase (1:100, ABC Vector Laboratories Inc. CA, USA) em triton ABC; f) marcação com peroxidase usando o cromógeno 3,3'diaminobenzidina (DAB, Sigma-Aldrich Chemie, Steinheim, Germany) e uma solução de peróxido de hidrogênio $0,01 \%$ em PB, sendo a reação freada com PB; g) os cortes foram montados nas lâminas com solução de montagem e mantidos por pelo menos $48 \mathrm{~h}$ à $37^{\circ} \mathrm{C}$; h) desidratação à temperatura ambiente e cobertura com lamínula utilizando Permount (Fisher Scientific, New Jersey, USA). Os cortes utilizados no ensaio imuno-histoquímico para marcação de Egr-1, 5HT e SP no NDR, NMR e CPME foram selecionados baseando-se no atlas estereotáxico Paxinos e Watson (2004) (Figura 4). A CPME, mais especificamente entre as lâminas I e 5 de Rexed, foi avaliada na porção medular correspondente à região das vértebras lombares quatro (L4) e cinco (L5). A imunorreatividade foi analisada por microscopia de luz (80i, Nikon), as imagens foram capturadas e as áreas selecionadas foram quantificadas pelo programa ImageJ (NIH/EUA). A quantificação da marcação para Egr-1 no NMR foi feita utilizando a opção cell counter; para 5HT as imagens foram recortadas nas dimensões 640x392pixels. Na quantificação da marcação para Egr-1 e 5HT no NDR as imagens foram recortadas nas dimensões 330x412pixels. Os recortes foram feitos para delimitar a área de interesse a ser quantificada. As dimensões originais das imagens foram, respectivamente, 1280x1024pixels e 640x512pixels para os ensaios com Egr-1 e 5HT. Foram quantificados nas áreas selecionadas os núcleos marcados para Egr-1 ou a área marcada para $5 \mathrm{HT}$ ou SP em pixels $/ \mathrm{cm}^{2}$. Foram avaliados 5 cortes por animal para cada estrutura e anticorpo avaliado, sendo utilizado 7 animais por grupo. Foi realizada a média dos números obtidos de núcleos marcados para Egr-1 ou da área marcada para $5 \mathrm{HT}$ ou SP dos cortes de cada animal, seguida da média de todos os animais pertencentes ao mesmo grupo. Os resultados representam a medida da 
densidade relativa de núcleos marcados para Egr-1 ou da imunorreatividade para $5 \mathrm{HT}$ ou SP nas diferentes regiões avaliadas de animais naive, sham ou estimulados.

Figura 5 - Estruturas onde foram feitas as análises imuno-histoquímicas.

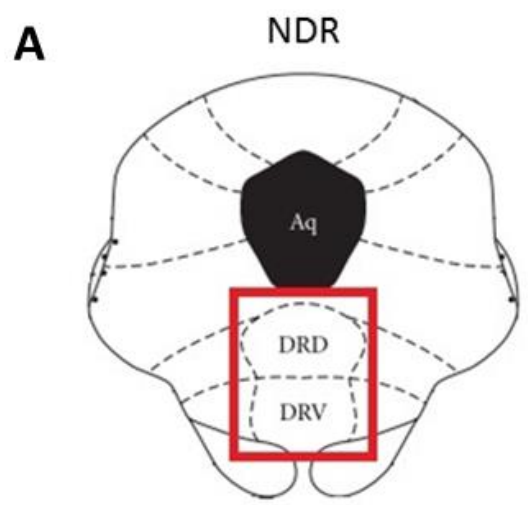

B

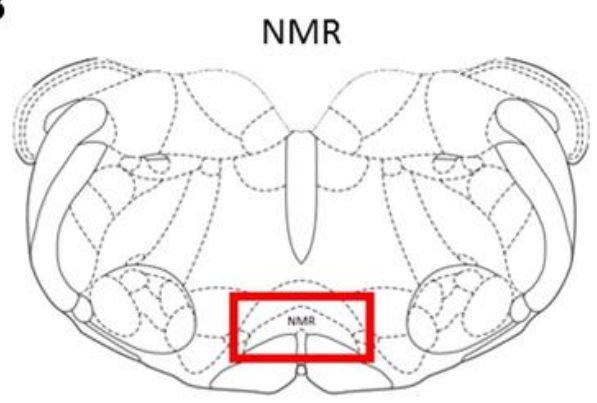

C CPME

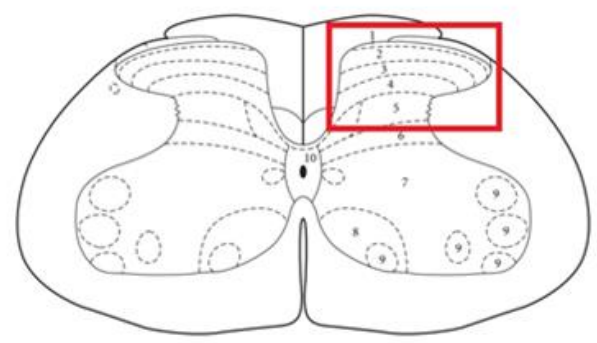

llustração das estruturas avaliadas nos ensaios imuno-histoquímicos. Painel A: Núcleo dorsal da rafe (NDR). Aqueduto cerebral (Aq). Rafe dorsal dorsal (DRD). Rafe dorsal ventral (DRV). Painel B: Núcleo magno da rafe (NMR). Painel C: Coluna posterior da medula espinhal (CPME), L4-L5. As áreas analisadas estão delimitadas pelos quadrados vermelhos. Fonte: (PAXINOS; WATSON, 2006).

\subsection{Análise estatística}

Os dados foram representados como média \pm e.p.m. A análise estatística foi gerada utilizando o programa GraphPad Prism 5 (GraphPad Software Inc.). A comparação estatística entre os grupos foi realizada usando a análise de variância de uma via (ANOVA), seguido pelo teste de Bonferroni. O índice de significância foi considerado de $p \leq 0,05$. 


\section{RESULTADOS}

\subsection{Efeito da ECM sobre a resposta nociceptiva mecânica}

$\mathrm{Na}$ tentativa de melhor elucidar os mecanismos envolvidos com a antinocicepção induzida pela ECM, animais submetidos a estimulação cortical e animais controles (naive e falso-estimulados) foram avaliados no teste nociceptivo. A ECM induziu um aumento significativo no limiar nociceptivo mecânico dos animais (62\% de aumento), em comparação com os animais controles, ratos naive e falsoestimulados (Figura 5). Os testes imuno-histoquímicos foram realizados em cortes obtidos de animais que foram previamente avaliados no teste nociceptivo, sendo condição absoluta para realização dos testes a ausência de nocicepção em ratos naive e falso-estimulados e aumento do limiar nociceptivo em ratos estimulados.

Figura 6 - Efeito da ECM sobre o limiar nociceptivo mecânico.

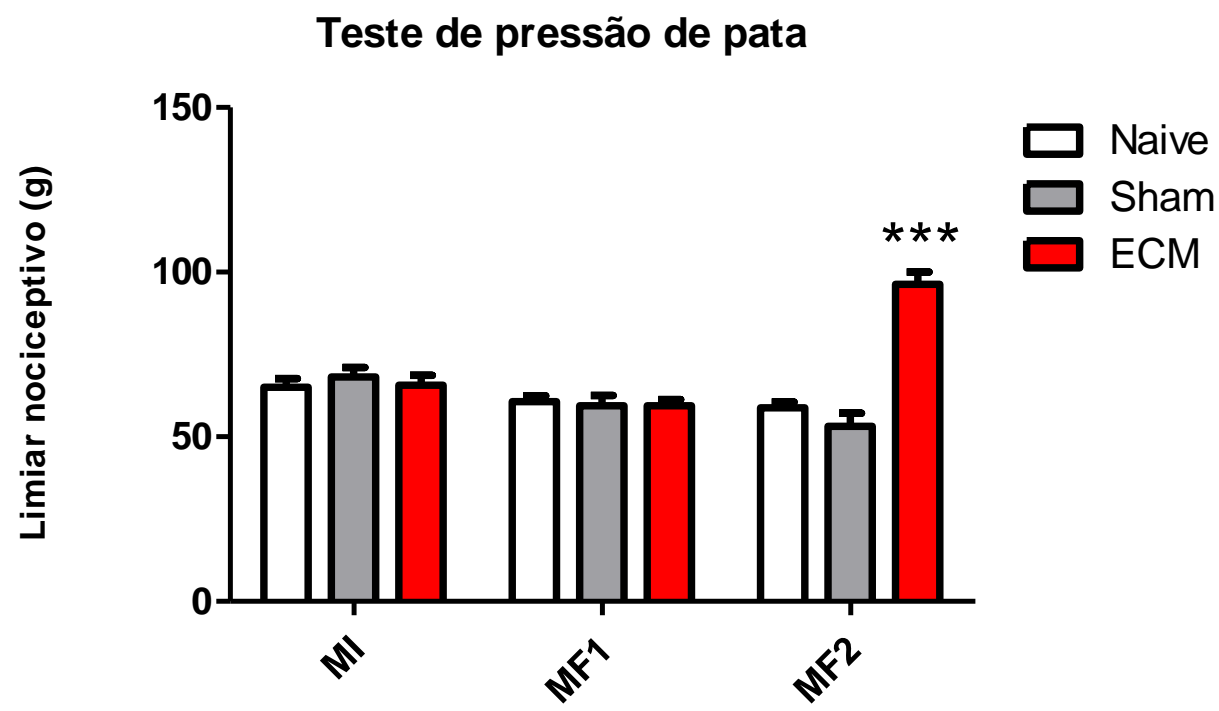

Os ratos foram avaliados antes do implante dos eletrodos transdurais (medida inicial, MI) e 7 dias após o implante (medida final, MF1 e após 15 minutos - MF2). Sham: animais falsoestimulados. ECM: animais submetidos a estimulação cortical. Os dados representam a média \pm e.p.m. de 7 animais por grupo. ${ }^{* *} \mathrm{p}<0,001$ em relação aos demais grupos 


\subsection{Efeito da ECM sobre ativação neuronal do NDR}

Considerando que a ativação de neurônios localizados no NDR está relacionado à ativação da via de analgesia descendente (PALAZZO et al., 2006; ZORMAN et al., 1982), avaliamos o padrão de ativação neuronal por Egr-1 no NDR. A ECM não interferiu com o padrão de ativação neuronal, vista por Egr-1, no NDR quando comparado com os grupos controles (Figura 6).

Figura 7 - Análise do padrão de ativação neuronal no NDR.
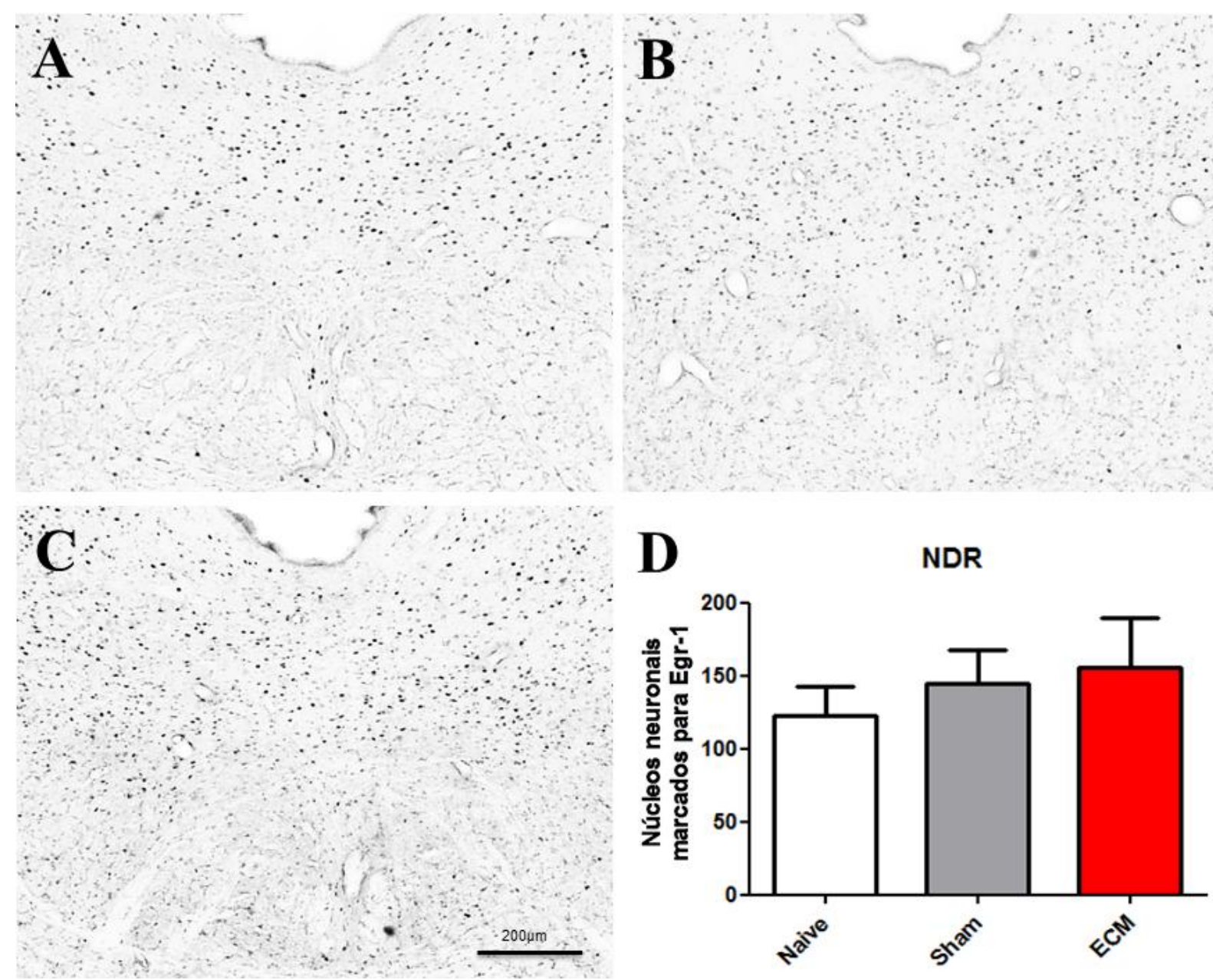

Imagem digital da marcação para Egr-1 em (A) animal naive, (B) não estimulado (sham) e (C) estimulado (ECM). (D) Análise quantitativa do número de núcleos neuronais marcados para Egr-1 por $\mathrm{cm}^{2}$. Os dados representam a média \pm e.p.m. de 5 cortes de 7 animais por grupo. 


\subsection{Efeito da ECM sobre a marcação para serotonina no NDR}

Dado que neurônios serotonérgicos do NDR são responsáveis pela modulação da analgesia (NISHIKAWA; SCATTON, 1983), avaliamos a marcação para 5HT no NDR. A ECM induziu um aumento de $75 \%$ na imunorreatividade para $5 \mathrm{HT}$ no NDR em relação aos grupos controles (Figura 7).

Figura 8 - Análise da marcação serotonérgica no NDR.
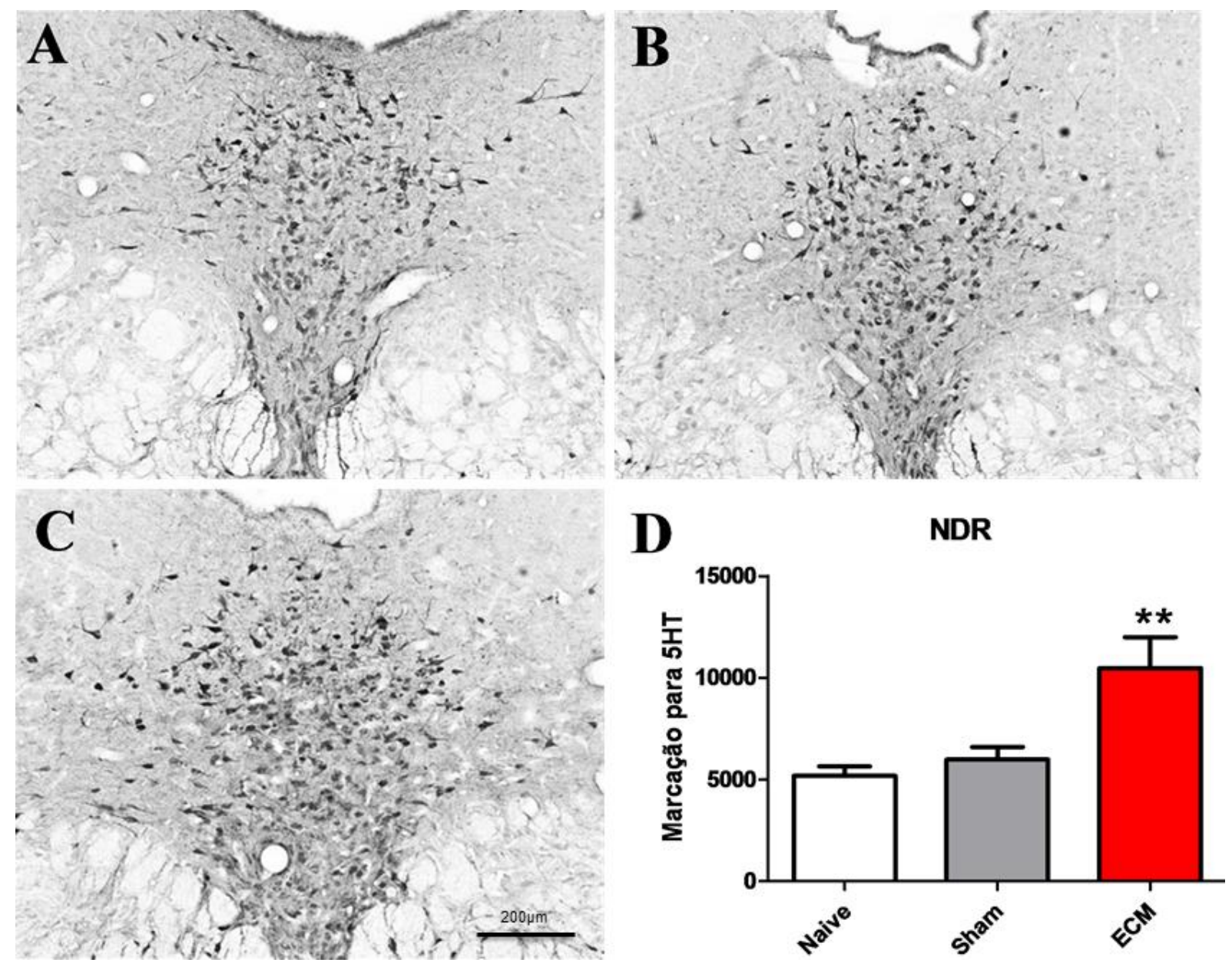

Imagem digital da marcação serotonérgica em (A) animal naive, (B) não estimulado (sham) e (C) estimulado (ECM). (D) Análise quantitativa da área total da imunorreatividade para $5 \mathrm{HT}$ por $\mathrm{cm}^{2}$. Os dados representam a média \pm e.p.m. de 5 cortes de 7 animais por grupo. ${ }^{* *} p<0,05$ em relação aos demais grupos. 


\subsection{Efeito da ECM sobre a ativação neuronal no NMR}

O NMR é um dos principais núcleos serotonérgicos cuja ativação resulta em inibição do estímulo nociceptivo (OLIVERAS et al., 1977). Assim, fomos avaliar o padrão de ativação do NMR por Egr-1. A ECM induziu um aumento de $67 \%$ na ativação neuronal no NMR, vista por Egr-1, em relação ao controles (Figura 8).

Figura 9 - Análise do padrão de ativação neuronal no NMR.

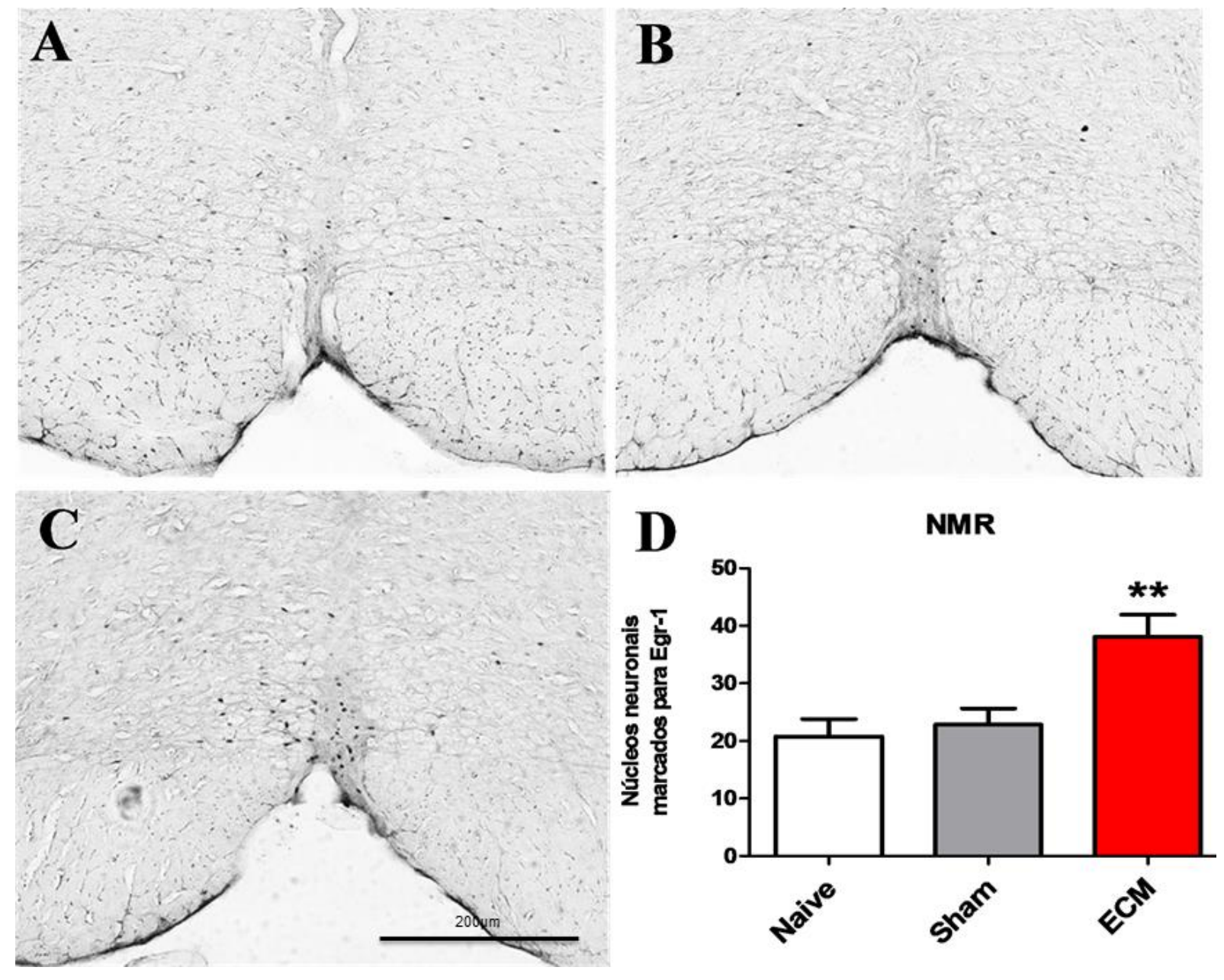

Imagem digital da marcação para Egr-1 em (A) animal naive, (B) não estimulado (sham) e (C) estimulado (ECM). (D) Análise quantitativa do número de núcleos neuronais marcados para Egr-1 por $\mathrm{cm}^{2}$.Os dados representam a média \pm e.p.m. de 5 cortes de 7 animais por grupo. ${ }^{* *} \mathrm{p}<0,05$ em relação aos demais grupos. 


\subsection{Efeito da ECM sobre a marcação para serotonina no NMR}

Uma vez que a liberação de 5HT de neurônios do NMR para a CPME é responsável por parte relevante da inibição nociceptiva da via de analgesia descendente (AUERBACH; FORNAL; JACOBS, 1985), fomos avaliar o padrão de marcação para 5HT no NMR. A ECM induziu um aumento de $92 \%$ na imunorreatividade para 5HT em relação aos grupos controles (Figura 9).

Figura 10 - Análise da marcação serotonérgica no NMR.

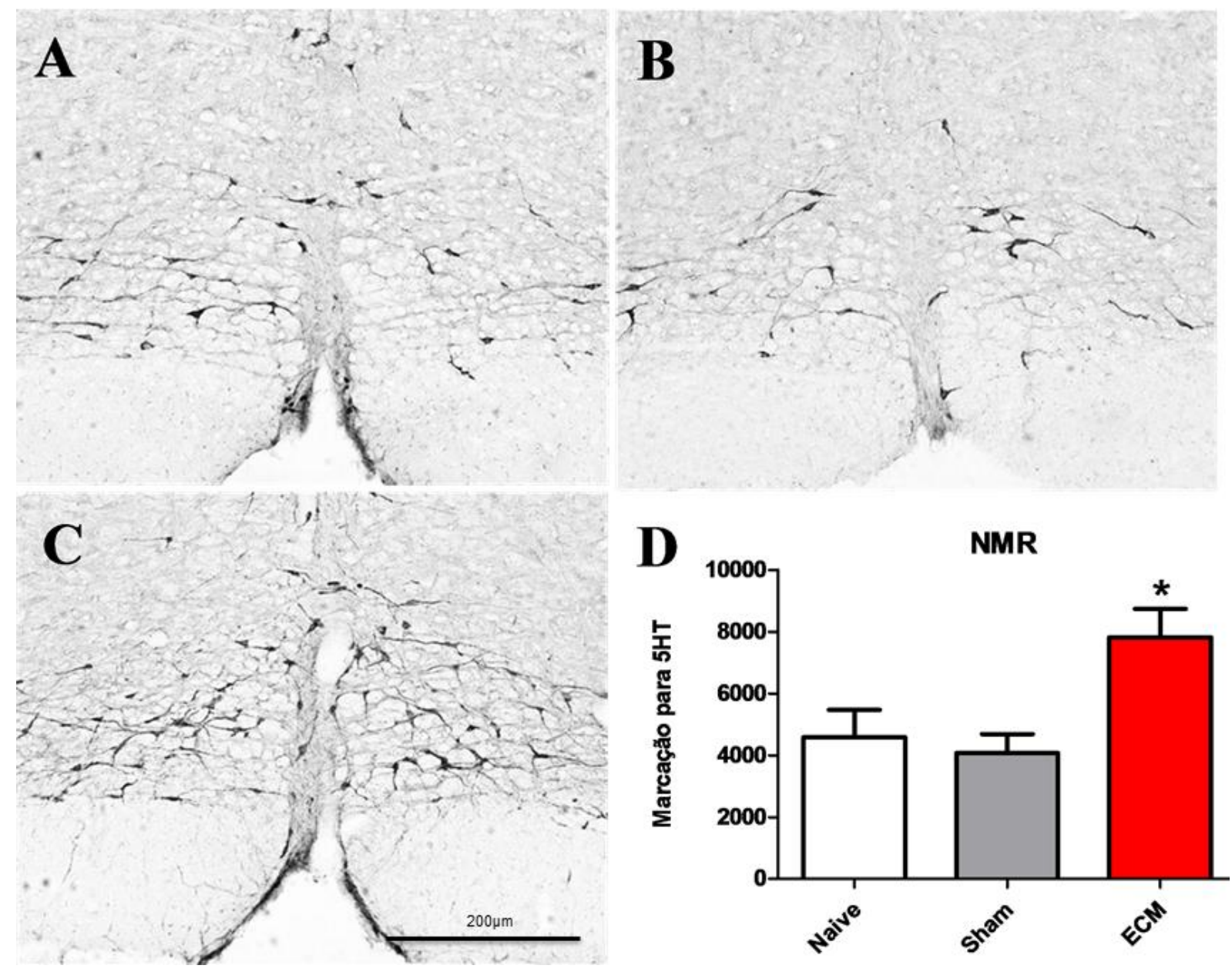

Imagem digital da marcação serotonérgica em (A) animal naive, (B) não estimulado (sham) e (C) estimulado (ECM). (D) Análise quantitativa da área total da imunorreatividade para $5 \mathrm{HT}$ por $\mathrm{cm}^{2}$. Os dados representam a média \pm e.p.m. de 5 cortes de 7 animais por grupo. ${ }^{*} p<0,05$ em relação aos demais grupos. 


\subsection{Efeito da ECM sobre a ativação neuronal na CPME}

A CPME é o sítio final onde as diferentes vias ascendentes e descendentes modulam a transmissão do estimulo nociceptivo de neurônios aferentes primários provenientes da periferia de forma facilitatória e inibitória (BASBAUM; FIELDS, 1984). Assim, fomos avaliar o padrão de ativação neuronal por Egr-1 na CPME. A ECM induziu uma diminuição de $48 \%$ na ativação neuronal na CPME, visto por Egr1, em relação ao grupo não estimulado (Figura 10).

Figura 11 - Análise do padrão de ativação neuronal na CPME.
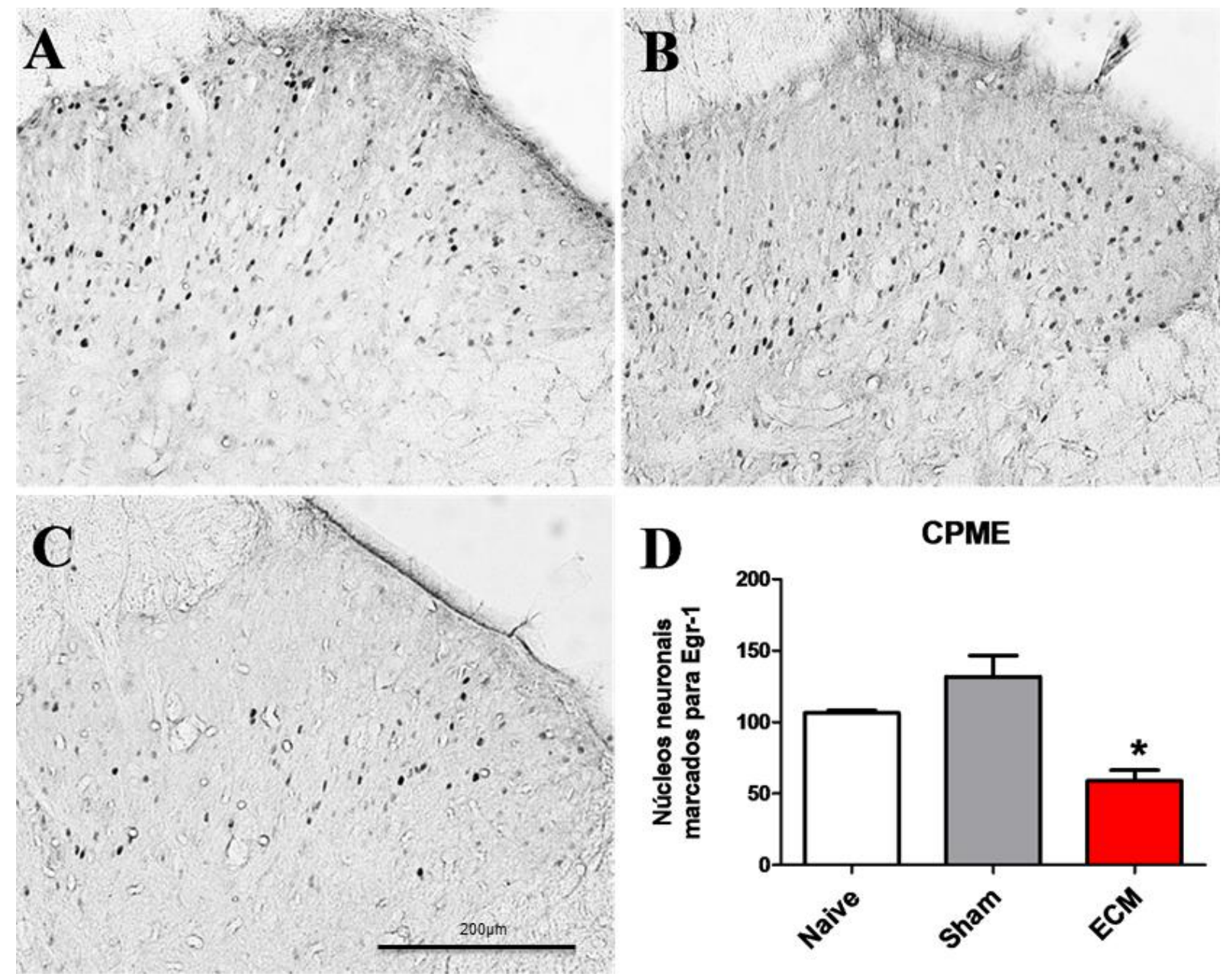

Imagem digital da marcação para Egr-1 em (A) animal naive, (B) não estimulado (sham) e (C) estimulado (ECM). (D) Análise quantitativa do número de núcleos neuronais marcados para Egr-1 por $\mathrm{cm}^{2}$. Os dados representam a média \pm e.p.m. de 5 cortes de 7 animais por grupo. ${ }^{*} p<0,05$ em relação ao grupo sham. 


\subsection{Efeito da ECM sobre a marcação de fibras SP-positivas na CPME}

Considerando que a SP é um dos principais neurotransmissores excitatórios liberados na CPME que medeiam a transmissão do estímulo nociceptivo da periferia para o sistema nervoso central (WALLIN; SCHOTT, 2002), avaliamos o padrão de marcação de SP na CPME. A ECM não alterou o padrão de marcação de SP, quando comparado com os grupos controles (Figura 11).

Figura 12 - Análise do padrão de marcação para SP na CPME.
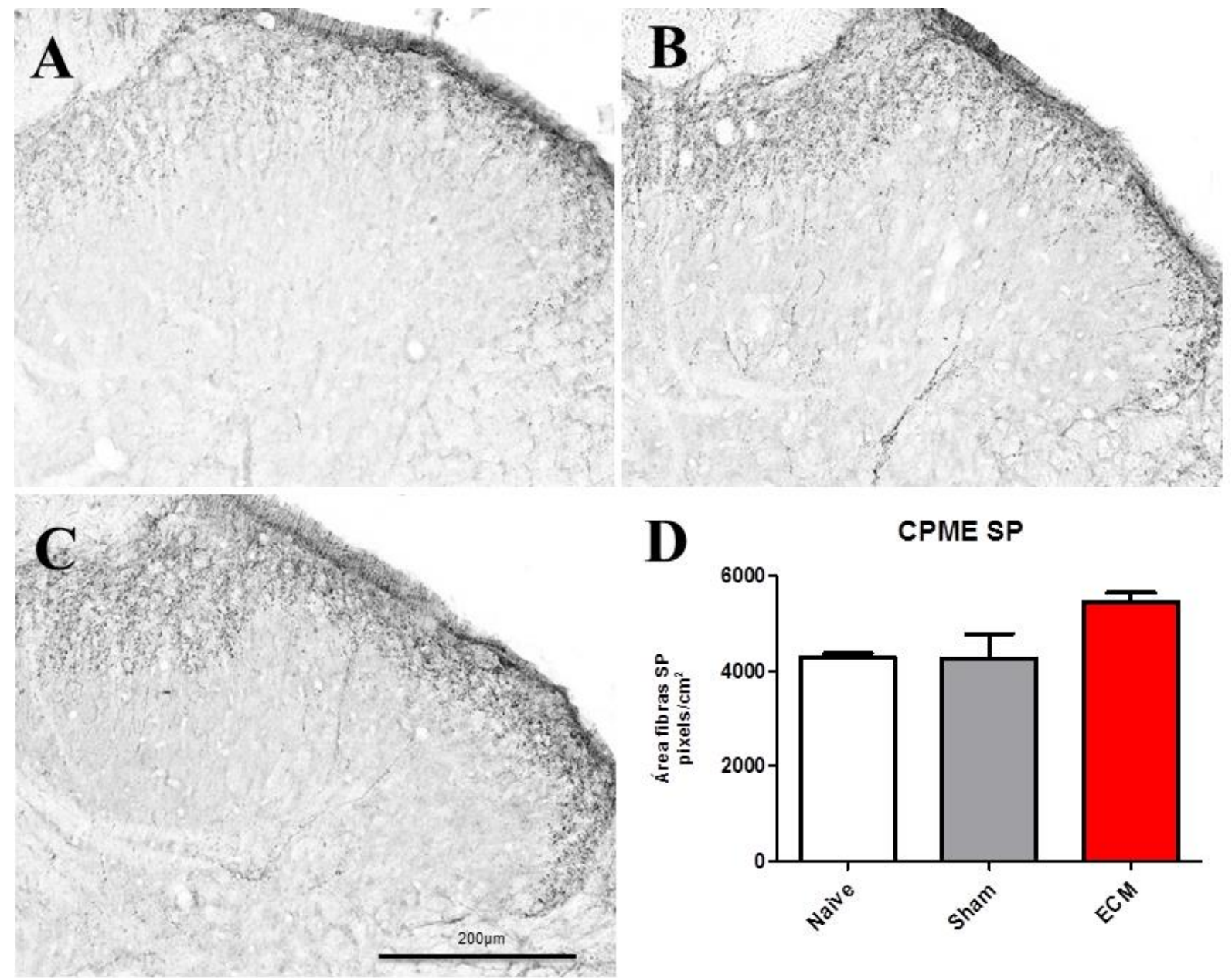

Imagem digital da marcação para SP em (A) animal naive, (B) não estimulado (sham) e (C) estimulado (ECM). (D) Análise quantitativa da imunorreatividade das fibras SP-positivas na CPME por $\mathrm{cm}^{2}$. Os dados representam a média \pm e.p.m. de 5 cortes de 7 animais por grupo. 


\section{DISCUSSÃO}

Considerando que a estimulação do córtex motor ativa a PAG (PAGANO et al., 2012) e que essa resposta é modulada principalmente pela via serotonérgica descendente, agindo sobre neurônios nociceptivos espinhais com a finalidade de inibir a transmissão do estimulo nociceptivo (VIISANEN; PERTOVAARA, 2010b), decidimos investigar o efeito da estimulação cortical sobre a ativação dos núcleos serotonérgicos NDR e NMR, envolvidos na via analgésica descendente, e sobre os neurônios da CPME.

A ECM induziu um aumento no limiar nociceptivo mecânico dos animais, quando comparado aos demais grupos controle, naive e falso-estimulado. Assim, as condições absolutas para dar continuidade aos ensaios foram: a ausência de nocicepção nos grupos controles, animais naive e falso-estimulados, e o aumento do limiar nociceptivo em animais submetidos à ECM.

O NDR apresenta grande heterogeneidade na sua população neuronal, incluindo grupos de neurônios que contém 5HT, neuropeptídeos como glutamato, SP, opióides ou GABA (HAJ-DAHMANE, 2001), sendo que tal variedade não se restringe à inibição, mas também à facilitação nociceptiva (WANG; NAKAI, 1994). Com relação à inibição nociceptiva, neurônios serotonérgicos do NDR recebem conexões excitatórias glutamatérgicas (GUIARD et al., 2005), levando a liberação de 5HT diretamente na CPME ou indiretamente no NMR e no tálamo (PALAZZO et al., 2006), resultando na ativação da via de analgesia descendente. Já frente à facilitação nociceptiva, os neurônios serotonérgicos do NDR também recebem conexões inibitórias de neurônios GABAérgicos (NISHIKAWA; SCATTON, 1983). A liberação de opióides no NDR inibe as aferências GABAérgicas e glutamatérgicas, agindo no aumento do efluxo de 5HT (TAO; AUERBACH, 2005). A interação entre essas diferentes populações neuronais tem sido proposta para a modulação da nocicepção decorrente da ativação do NDR (CICHEWICZ, 2004; MANZANARES et al., 1999; WELCH, 2009).

A ECM não alterou o padrão de ativação neuronal no NDR nos animais estimulados, quando comparados aos demais grupos controle. Considerando que a ação GABAérgica exerce efeito inibitório sobre diversas populações neuronais envolvidas na antinocicepção no NDR, incluindo a população serotonérgica envolvida na modulação da via de analgesia descendente (WANG; NAKAI, 1994), e 
que a localização da marcação para Egr-1 e para 5HT no NDR se mostraram bastante divergentes entre si, sugerimos que a atividade neuronal vista por Egr-1 neste núcleo pode ser retrato da atividade de diferentes populações de neurônios, não somente de neurônios serotonérgicos.

Com relação à marcação para $5 \mathrm{HT}$ no NDR, os resultados obtidos demonstraram que a ECM induziu um aumento na marcação desse neurotransmissor no NDR quando comparado aos grupos controles. Esse resultado corrobora com resultados obtidos por outros autores que demonstram aumento da produção de 5HT (PALAZZO et al., 2004; 2006) e de transportadores de 5HT no NDR de animais submetidos a estímulos nociceptivos (ROJO et al., 2012). Somando essas evidências e considerando que a ECM ativa a PAG (PAGANO et al., 2012) e que esta possui neurônios que exercem atividade excitatória constante sobre populações serotonérgicas da via de analgesia descendente no NDR (BAJIC; COMMONS, 2010), podemos sugerir que a antinocicepção resultante da estimulação cortical pode ser decorrente, em parte, do aumento da produção serotonérgica de neurônios do NDR.

O NMR possui neurônios serotonérgicos e distintas populações de células nãoserotonérgicas classificadas como células ON e células OFF, que exercem, respectivamente, atividade facilitatória ou inibitória em relação a estímulos nociceptivos, além de células neutras, cujo papel ainda não está claro na modulação nociceptiva (BRINK et al., 2006). A população neuronal serotonérgica do NMR tem sido considerada primordial na via de analgesia descendente, e embora compreenda somente cerca de 10 a $20 \%$ da população do NMR, é a maior fonte de $5 \mathrm{HT}$ para a CPME (MASON; GAO, 1998). Estes neurônios serotonérgicos presentes no NMR são ativados diretamente pela PAG e agem especificamente na modulação nociceptiva (AUERBACH; FORNAL; JACOBS, 1985).

Em nossa análise, a ECM induziu a ativação neuronal do NMR, comparado aos demais grupos controles. Dado que a estimulação cortical ativa a PAG (PAGANO et al., 2012) e que esta tem influência excitatória direta nos neurônios serotonérgicos do NMR (BEITZ, 1982; HERMANN et al., 1997), sugerimos que a ECM induz, indiretamente via ativação da PAG, um efeito excitatório nos neurônios serotonérgicos do NMR, resultando na inibição dos neurônios nociceptivos presentes na CPME. Tais resultados coincidem com os obtidos por Viisanen e Pertoovara (2010a), que demonstraram que o bloqueio da ativação do NMR, com 
administração de muscimol, um agonista GABAérgico, impede a analgesia induzida pela estimulação cortical. Entretanto, é possível que a ativação vista em nossa análise seja originária, além dos neurônios serotonérgicos, das células OFF presentes no NMR e, que quando ativadas, inibem a transmissão nociceptiva (HEINRICHER; BARBARO; FIELDS, 1989). Confirmando a participação dos neurônios serotonérgicos do NMR no aumento do limiar nociceptivo induzido pela ECM, observamos um aumento na imunomarcação para 5HT no NMR após estimulação cortical. Com isso ressaltamos que a $5 \mathrm{HT}$ pode estar contribuindo com o efeito antinociceptivo induzido pela estimulação cortical, já que a inibição dos neurônios de projeção nociceptivo na CPME depende desse suporte serotonérgico (MASON, 2001).

Na CPME o aumento da marcação dos proto-oncogenes está associado com a marcação de neurônios nociceptivo ativados (HUNT et al., 1987). Nesse sentido, foi demonstrado um aumento da marcação para os proto-oncogenes c-Fos e Egr-1 em neurônios localizados na CPME em resposta a estímulos nocivos periféricos em ratos, como estimulação elétrica, química, térmica e modelos de inflamação aguda e crônica (BURITOVA; HONORÉ; BESSON, 1995; HERGEDEN et al., 1991; HUNT et al., 1987; LANTERI-MINET et al., 1993). Considerando que a ativação da via de analgesia descendente modula a transmissão do estímulo nociceptivo inibindo os neurônios nociceptivos presentes na CPME (BASBAUM; FIELDS, 1984), fomos investigar o padrão de ativação neuronal dos neurônios nociceptivos espinhais visto pela marcação para Egr-1.

A ECM induziu inibição dos neurônios nociceptivos presentes na CPME quando comparado com os grupos controles. Esses resultados convergem com outros que sugerem uma relação direta entre antinocicepção e inibição da marcação de proto-oncogenes na CPME (GOGAS et al., 1991; MORGAN; CURRAN, 1989). Ainda, esses resultados corroboram com dados obtidos por Senapati e colaboradores (2005b), que demonstraram, por eletrofisiologia, que a estimulação elétrica subdural do córtex motor inibe a ativação de neurônios nociceptivos na CPME. Em adição, esses resultados corroboram também com dados prévios obtidos pelo nosso grupo, onde demonstramos que a ECM inibe a ativação de neurônios espinhais, visto pela marcação para Egr-1 e Fos, em animais com neuropatia periférica (PAGANO et al., 2011). 
A CPME é o local onde a via serotonérgica do sistema de analgesia descendente consolida a inibição da transmissão do estimulo nociceptivo proveniente da periferia (MILLAN; GIRARDON; BERVOETS, 1997). A SP presente nos terminais das fibras de pequeno e médio calibre dos neurônios aferentes primários, quando liberada frente a um estímulo nociceptivo, atua em receptores NK1 presentes em neurônios de projeção, sendo um dos peptídeos responsáveis pela condução nociceptiva na CPME (WALLIN; SCHOTT, 2002). Levando em conta essas evidências, analisamos o padrão de marcação de SP na CPME dos animais submetidos à ECM e nenhuma diferença foi obtida em relação aos grupos controle. Com esses resultados, sugerimos que a ECM induz a inibição do estímulo nociceptivo na CPME, e que essa inibição seja provavelmente pós-sináptica, ou seja, via neurônios de projeção, já que a liberação de SP dos terminais das fibras aferentes primárias não exibiu nenhuma alteração.

Os resultados obtidos mais uma vez demonstram o papel do córtex motor no controle da resposta nociceptiva. Considerando que essa intervenção cirúrgica é utilizada para tratamento de dor neuropática refratária e que somente $50 \%$ dos pacientes se beneficiam com essa técnica (FAGUNDES-PEREYRA et al., 2010; NGUYEN et al., 2000), um melhor entendimento dos mecanismos de inibição do estímulo nociceptivo por ela desencadeados podem, posteriormente, colaborar com o aprimoramento dessa técnica, tornando-a mais efetiva e aumentar a sua probabilidade de sucesso em casos em que, até então, ela se mostrou ineficaz. Esse conhecimento pode também esclarecer melhor o papel de áreas funcionais envolvidas nesse efeito analgésico, possibilitando aos pacientes cujo comprometimento é decorrente de alguma dessas áreas, a associação de fármacos à terapia, e consequentemente, colaborar com o restabelecimento de suas funções. 


\section{CONCLUSÃO}

Os resultados sugerem que a ECM ativa neurônios serotonérgicos no NDR e no NMR, levando a inibição de neurônios nociceptivos presentes na CPME, via 5HT, consequentemente aumentando o limiar nociceptivo. Esses dados reforçam o envolvimento do córtex motor na via de analgesia descendente e enfatizam a participação do sistema serotonérgico no efeito antinociceptivo induzido pela estimulação cortical. 


\section{REFERÊNCIAS*}

AGGLETON, J. P. The amygdala: neurobiological aspects of emotion, memory and mental dysfunction. New York: Wiley-Liss, 1992.

ALMEIDA, T. F.; ROIZENBLATT, S.; TUFIK, S. Afferent pain pathways: a neuroanatomical review. Brain Res., v. 1000, p. 40-56, 2004.

AUERBACH, S.; FORNAL, C.; JACOBS, B. L. Response of serotonin-containing neurons in nucleus raphe magnus to morphine, noxious stimuli, and periaqueductal gray stimulation in freely moving cats. Experimental Neurology, v. 88, p. 609-628, 1985.

BAJIC, D.; COMMONS, K. G. Acute noxious stimulation modifies morphine effect in serotonergic but not dopaminergic midbrain areas. Neuroscience, v. 166, p. 720-729, 2010.

BANDLER, R.; SHIPLEY, M. T. Columnar organization in the midbrain periaqueductal gray: modules for emotional expression? Trends Neurosci., v. 17, p. 379-389, 1994.

BASBAUM, A. I.; FIELDS, H. L. Endogenous pain control systems: brainstem spinal pathways and endorphin circuitry. Annu. Rev. Neurosci., v. 7, p. 309-338, 1984.

BRAZ, J. M.; ENQUIST, L. W.; BASBAUM, A. I. Inputs to serotonergic neurons revealed by conditional viral transneuronal tracing. J. Comp. Neurol., v. 514, p. 145-160, 2009.

BECKMANN, A. M.; WILCE, P. A. Egr transcription factors in the nervous system. Neurochem. Int., v. 31, p. 477-510, 1997.

BEHBEHANI, M. M.; FIELDS, H. L. Evidence that an excitatory connection between the periaqueductal gray and nucleus raphe magnus mediates stimulation produced analgesia. Brain Res., v. 170, p. 85-93, 1979.

BEITZ, A. J. The organisation of afferent projections to the midbrain periaqueductal grey of the rat. Neuroscience, v. 7, p. 133-159, 1982.

BINSHTOK, A. M; WANG, H; ZIMMERMANN, K; AMAYA, F.; VARDHE, D; SHI, L; BRENNER, G. J; JI, R; BEAN; B. P, WOOLF, C. J; SAMAD; T. A. Nociceptors are interleukin $1 \beta$ sensors. The Journal of Neuroscience, v. 28, p. 14062-14073, 2008.

BRINK, T. S.; HELLMAN, K. M.; LAMBERT, A. M.; MASON, P. Raphe magnus neurons help protect reactions to visceral pain from interruption by cutaneous pain. $\mathbf{J}$ Neurophysiol., $\mathbf{v}$. 96, p. 3423-3432, 2006.

BROMM, B.; TREEDE, R. D. Human cerebral potentials evoked by co2 laser stimuli causing pain. Exp. Brain. Res., v. 67, p. 153-162, 1987.

BURITOVA, J.; HONORÉ, P.; BESSON, J. M. Indomethacin reduces both Krox-24 expression in the rat lumbar spinal cord and inflammatory signs following intraplantar carrageenan. Brain Res., v. 674, p. 211-220, 1995.

*De acordo com:

ASSOCIAÇÃO BRASILEIRA DE NORMAS TÉCNICAS. NBR 6023: informação e documentação: referências: elaboração. Rio de Janeiro, 2002. 
BUSHNELL, M. C.; DUNCAN, G. H.; HOFBAUER, R. K.; HA, B.; CHEN, JI.; CARRIER, B. Pain perception: is there a role for primary somatosensory cortex? Proc. Natl. Acad. Sci. U S A., v. 96, p. 7705-7709, 1999.

CANAVERO, S.; BONICALZI, V. Therapeutic extradural cortical stimulation for central and neuropathic pain: a review. Clin. J. Pain., v. 18, p. 48-55, 2002.

CICHEWICZ, D. L. Synergistic interactions between cannabinoid and opioid analgesics. Life Sci., v. 74, p. 1317-24, 2004.

CURTIS, D. R.; HOSLI, L.; JOHNSTON, G. A. Inhibition of spinal neurons by glycine. Nature, v. 215, p.1502-1503, 1967.

CLEMENT, C. I.; KEAY, K. A.; PODZEBENKO, K.; GORDON, B. D.; BANDLER, R. Spinal sources of noxious visceral and noxious deep somatic afferent drive onto the ventrolateral periaqueductal gray of the rat. J. Comp. Neurol., v. 425, p. 323-344, 2000.

CROUL, S.; RADZIEVSKY,A.; SVERSTIUK, A.; MURRAY, M. NK1, NMDA, 5HT1a, and $5 \mathrm{HT} 2$ Receptor binding sites in the rat lumbar spinal cord: modulation following sciatic nerve crush. Experimental Neurology, v. 154, p. 66-79, 1998.

DAHLSTROM, A.; FUXE, K. Evidence for existence of monoamine containing neurons in the central nervous system. I Demonstration of monoamines in cell bodies of brain stem neurons. Acta Physiol. Scand., (Suppl. 232) v. 62, p. 1-55.

DJOURI, D.; LAWSON, S. N. A-beta fiber nociceptive primary afferent neurons: a review of incidence and properties in relation to other afferent A-fiber neurons in mammals. Brain Research Reviews, v. 46, p. 131-145, 2004.

DOSTROVSKY, J. O.; CRAIG, A. D. Ascending projection systems. In: MCMAHON, S. B.; KOLTZENBURG, M. (Ed.). Wall and Melzack's Textbook of Pain. Philadelphia: Elsevier, 2006. p. 187-203.

FAGUNDES-PEREYRA, W. J.; TEIXEIRA, M. J.; REYNS, N.; TOUZET, G.; DANTAS, S.; BLOND, S. Motor cortex electric stimulation for the treatment of neuropathic pain. Arq. Neuropsiquiatr., v. 68, p. 923-929, 2010.

FIELDS, H. L.; BASBAUM, A. I; HEINRICHER, M. M. Central nervous systems mechanisms of pain modulation. In: MCMAHON, S. B.; KOLTZENBURG, M. (Ed.). Wall and Melzack's Textbook of pain. Philadelphia: Elsevier, 2006. p. 125-142.

FIELDS, H. L.; HEINRICHER, M. M.; MASON, P. Neurotransmitters in nociceptive modulatory circuits. Annu. Rev. Neurosci., v. 14, p. 219-245, 1991.

FONOFF, E. T.; DALE, C. S.; PAGANO, R. L.; PACCOLA, C. C.; BALLESTER, G.; TEIXEIRA, M. J.; GIORGI, R. Antinociception induced by epidural motor cortex stimulation in naive conscious rats is mediated by the opioid system. Behav. Brain. Res., v. 196, p. 63-70, 2009a.

FONOFF, E. T.; PEREIRA JR, J. P.; CAMARGO, L. V.; DALE, C. S.; PAGANO, R. L.; BALLESTER, G.; TEIXEIRA, M. J. Funcional mapping of the motor cortex of rat using transdural electrical stimulation. Behav. Brain. Res., v. 202, p. 138-141, 2009b. 
GARCIA-LARREA, L.; PEYRON, R.; MERTENS, P.; GREGOIRE, M. C.; LAVENNE, F.; LE BARS, D.; CONVERS, P.; MAUGUIĖRE, F.; SINDOU, M.; LAURENT, B. Electrical stimulation of motor cortex for pain control: a combined PET-scan and electrophysiological study. Pain, v. 83, p. 259-73, 1999.

GOGAS, K. R.; PRESLEY, R. W.; LEVINE, J. D.; BASBAUM, A. I. The antinociceptive action of supraspinal opioids results from an increase in descending inhibitory control: correlation of nociceptive behavior and c-fos expression, Neuroscience, v. 42, p. 617-628, 1991.

GRAHAM, B. A.; BRICHTA, A. M.; CALLISTER, R. J. Moving from an averaged to specific view of spinal cord pain processing circuits. J. Neurophysiol., v. 98, p. 1057-1063, 2007.

GUIARD. B. R.; FROGER, N.; HAMON, M.; GARDIER, A .M.; LANFUMEY, L. Sustained pharmacological blockade of NK 1 substance $P$ receptorscauses functional desensitization of dorsal raphe 5-HT 1Aautoreceptors in mice. J. Neurochem., v. 95, p. 1713-1723, 2005.

HAJ-DAHMANE, S. D2 -like dopamine receptor activation excites rat dorsal raphe 5-HT neurons in vitro. Eur. J. Neurosc., v. 14, p. 125-134, 2001.

HEINRICHER, M. M.; BARBARO, N. M.; FIELDS, H. L. Putative nocicetive modulating neurons in the rostral ventromedial medulla of the rat: firing of on and off-cells is related to nociceptive responsiveness. Somatosens. Mot Res., v. 6, p. 427-439, 1989.

HERBERT, H.; SAPER, C. B. Organization of medullary adrenergic and noradrenergic projections to the periaqueductal gray matter in the rat. J. Compar. Neurol., v. 315, p. 34-52, 1992.

HERDEGEN, T.; KOVARY, K.; LEAH, J.; BRAVO R. Specific temporal and spatial distribution of JUN, FOS, and KROX-24 proteins in spinal neurons following noxious transsynaptic stimulation. J. Comp. Neurol., v. 313, p. 178-191, 1991.

HERDEGEN, T.; LEAH, J. D. Inducible and constitutive transcription factors in the mammalian nervous system: control of gene expression by Jun, Fos and Krox, and CREB/ATF proteins. Brain Res. Brain. Res. Rev, v. 28, p. 370-490,1998.

HERMANN, D. M.; LUPPI, P. H.; PEYRON, C.; HINCKEL, P.; JOUVET, M. Afferent projections to the rat nuclei raphe magnus, raphe pallidus and reticularis gigantocellularis pars alpha demonstrated by iontophoretic application of choleratoxin (subunit B). J. Chem. Neuroanat., v. 13, p. 1-21, 1997.

HERRERA, D. G.; ROBERTSON, H. A. Activation of c-Fos in the brain. Prog. Neurobiol., v. 50, p. 83-107, 1996.

HUNT, S. P.; PINI, A.; EVAN, G. Induction of c-fos-like protein in spinal cord neurons following sensory stimulation. Nature, v. 328, p. 632-634, 1987.

JASMIN, L.; RABKIN, S. D.; GRANATO, A.; BOUDAH, A.; OHARA, P. T. Analgesia and hyperalgesia from gaba-mediated modulation of the cerebral cortex. Nature, v. 424, p. 316-320, 2003.

JESSEL, T.; KELLY, D. D. Pain and analgesia. In: KANDELL, E. R. S.; JESSEL, T. M. (Ed.). Principles of neuroscience. 1991. p. 385-399

JULIUS, D.; BASBAUM, A. I. Molecular mechanisms of nociception. Nature, v. 413, p. 203210, 2001. 
KANDEL, E. R; SCHWARTZ, J. H; JESSELL, T. M. (4Ed) Principles of neural science. New York: Mc-Graw-Hill, 2000. p 487.

KEAY, K. A.; BANDLER, R. Deep and superficial noxious stimulation increases Foslike immunoreactivity in different regions of the midbrain periaqueductal grey of the rat. Neurosci. Lett., v.154, p. 23-26, 1993.

KEAY, K. A.; CLEMENT, C. I.; OWLER, B.; DEPAULIS, A.; BANDLER, R. Convergence of deep somatic and visceral nociceptive information onto a discrete ventrolateral midbrain periaqueductal gray region. Neuroscience, v. 61, p. 727-732, 1994.

KUHAR, M. J.; PERT, C. B.; SNYDER, S. H. Regional distribution of opiate receptor binding in monkey and human brain. Nature, v. 245, p. 447-450, 1973.

LANTERI-MINET, M.; ISNARDON, P.; DE POMMERY, J.; MENETREY, D. Spinal and hindbrain structures involved in visceroception and visceronociception as revealed by the expression of Fos, Jun and Krox-24 proteins. Neuroscience, v. 55, p. 737-753, 1993.

LU, Y. Synaptic wiring in the deep dorsal horn. Focus on" local circuit connections between hamster laminae III and IV dorsal horn neurons". Journal of Neurophysiology, v. 99, p. 1051-1052, 2008.

MALCANGIO, M.; BOWERY, N. G. GABA and its receptors in the spinal cord. Trends Pharmacol. Sci., v. 17, p. 457-462, 1996.

MANZANARES, J.; CORCHERO, J.; ROMERO, J.;FERNANDEZ-RUIZ, J. J.; RAMOS, J. A; FUENTES, J. A. Pharmacological and biochemical interactions between opioids and cannabinoids. Trends Pharmacol. Sci., v. 20, p. 287-294, 1999.

MASON, P. Contributions of the medullary raphe and ventromedial reticular region to pain modulation and other homeostatic functions. Annu. Rev. Neurosci., v. 24, p. 737-777, 2001.

MASON, P.; GAO, K. Raphe magnus serotonergic neurons tonically modulate nociceptive transmission. Pain Forum., v. 7, p. 143-150, 1998.

MAZARIO, J.; BASBAUM, A. I. Contribuition of substance $P$ and neurokinin $A$ to the differential injury-induced thermal and mechanical responsiveness of lamina I and $V$ neurons. J. Neurosc., v. 27, p. 762-770, 2007.

MELZACK, R.; WALL, P. D. Pain mechanisms: a new theory. Science, v. 150, p. 971-979, 1965.

MERSKEY, H.; BOGDUK, N. Classification of chronic pain: Descriptions of chronic pain syndromes and definitions of pain terms. Seattle: IASP Press, 1994.

MEYER, R. A.; RINGKAMP, M.; CAMPBELL, J. N.; RAJA, S. N. Peripheral mechanisms of cutaneous nociception.. In: MCMAHON, S. B.; KOLTZENBURG, M. (Ed.). Wall and Melzack's Textbook of Pain. Philadelphia: Elsevier, 2006. p. 3-34.

MILLAN, M. J. Descending control of pain. Prog. Neurobiol., v. 66, p. 355-474, 2002.

MILLAN, M. J.; GIRARDON, S., BERVOETS, K. 8-OH-DPAT-induced, spontaneous tailflicks in the rat are facilitated by the selective serotonin (5-HT2C) agonist, RO 60-0175: 
blockade of its actions by the novel 5-HT2C

Neuropharmacology, 36, p. 743-745, 1997.

receptor antagonist SB 206,553.

MILLAN, M. J. The Induction of Pain: An Integrative Review. Prog. Neurobiol., v. 57, p. 1164, 1999.

MORGAN, J. I.; CURRAN, T. Stimulus-transcription coupling in neurons: role of cellular immediate-early genes. Trends. Neurosci., v.12, p. 459-462, 1989.

NGUYEN, J. P.; LEFAUCHEUR, J. P.; DECQ, P.; UCHIYAMA, T.; CARPENTIER, A.; FONTAINE, D.; BRUGIERES, P.; POLLIN, B.; FEVE, A.; ROSTAING, S.; CESARO, P.; KERAVEL, Y. Chronic motor cortex stimulation in the treatment of central and neuropathic pain. Correlations between clinical, electrophysiological and anatomical data. Pain, v. 82, p. 245-251, 1999.

NGUYEN, J. P.; LEFAUCHER, J. P.; LE GUERINEL, C.; EIZENBAUM, J. F.; NAKANO, N.; CARPENTIER, A.; BRUGIÈRES, P.; POLLIN, B.; ROSTAING, S.; KERAVEL, Y. Motor cortex stimulation in the treatment of central and neuropathic pain. Arch. Med. Res., v. 31, p. 263-265, 2000.

NISHIKAWA, T.; SCATTON, B. Evidence for a GABAergic inhibitory influence on serotonergic neurons originating from the dorsal raphe. Brain Res., v. 279, p. 325-329, 1983.

NUTI, C.; PEYRON, R.; GARCIA-LARREA L.; BRUNON, J.; LAURENT, B.; SINDOU, M.; MERTENS, P. Motor cortex stimulation for refractory neuropathic pain: four year outcome and predictors of efficacy. Pain, v. 118, p. 43-52, 2005.

OHARA, P. T.; VIT, J. P.; JASMIN, L. Cortical modulation of pain. Cell. Mol. Life Sci., v. 62 , p. 44-52, 2005.

OLIVERAS, J. L.; BOURGOIN, S.; HERY, F.; BESSON, J. M.; HAMON, M. The topographical distribution of serotoninergic terminals in the spinal cord of the cat: biochemical mapping by the combined use of microdissection and microassay procedures. Brain Res., v. 138, p. 393-406, 1977.

PAGANO, R. L.; ASSIS, D. V.; CLARA, J. A.; ALVES, A. S.; DALE, C. S.; TEIXEIRA, M. J.; FONOFF, E. T.; BRITTO, L. R. Transdural motor cortex stimulation reverses neuropathic pain in rats: a profile of neuronal activation. Eur. J. Pain, v. 15, p. 268-277, 2011.

PAGANO, R. L.; FONOFF, E. T.; DALE, C. S.; BALLESTER, G.; TEIXEIRA, M. J.; BRITTO, L. R. Motor cortex stimulation inhibits thalamic sensory neurons and enhances activity of PAG neurons: possible pathways for antinociception. Pain, v. 153, p. 2359-2369, 2012.

PALAZZO, E.; DE NOVELLIS, V.; PETROSINO, S.; MARARESE, I.; VITA, D.; GIORDANO, C.; DI MARZO, V.; MANGONI, G. S.; ROSSI, F.; MAIONE, S. Neuropathic pain and the endocannabinoid system in the dorsal raphe: pharmacological treatment and interactions with the serotonergic system. Eur. J. Neurosc., v. 24, p. 2011-2020, 2006.

PALAZZO, E.; GENOVESE, R.; MARIANI, L.; SINISCALCO, D.; MARABESE, I.; DE NOVELLIS, V.; ROSSI, F.; MAIONE, S. Metabotropic glutamate receptor 5 and dorsal raphe serotonina release in inflammatory pain in rat. Eur. J. Pharmacol., v. 492, p. 169-176, 2004.

PAXINOS, G. W.; WATSON, C. The rat brain in stereotaxic coordinates. San Diego: CA: Academic Press, 2006. 
PIMENTA, C. A. M.; KOIZUMI, M. S.; TEIXEIRA, M. J. Dor crônica e depressão: Estudo em 92 doentes. Revista da Escola de Enfermagem da USP, v. 34, p. 76-83, 2000.

PLONER, M.; GROSS, J.; TIMMERMAN. L.; SCHNITZLER, A. Pain processing is faster than tactile processing in the human brain. The Jounal of Neuroscience, v. 26, p. 10879-10882, 2006.

RANDALL, L. O.; SELITTO, J. J. A Method for measurement of analgesic activity on inflamed tissue. Arch. Int. Pharmacodyn. Ther., v. 111, p. 409-419, 1957.

RASCHE, D.; RUPPOLT, M.; STIPPICH, C.; UNTERBERG, A.; TRONNIER, V. M. Motor cortex stimulation for long-term relief of chronic neuropathic pain: a 10 year experience. Pain, v. 121, p. 43-52, 2006.

REXED, B. The cytoarchtectonic organization of the spinal cord in the cat. J. Comp. Neurol., v. 96, p. 415-495, 1952.

ROSENFELD, J. P. Interacting brain stem components of opiate-activated, descending, pain-inhibitory systems. Neurosci. Biobehav. Rev., v. 18, p. 403-409, 1994.

ROJO, M. L.; RODRÍGUEZ-GASTELUMENDI, A.; PAZOS, A.; DÍAZ, A. Differencial adaptative changes on serotonine and noradrenaline transporter in a rat model of peripheral neuropathic pain. Neuroscience Letters, v. 515, p. 181-186, 2012.

RUSINA, R.; VACULIN, S.; YAMAMOTOVA, A.; BAREK, S.; DVORAKOVA, H.; ROKYTA, R. The effect of motor cortex stimulation in deafferentated rats. Neuro. Endocrinol. Lett. v. 26, p. 283-288, 2005.

SAGAR, S. M.; SHARP, F. R.; CURRAN, T. Expression of c-fos protein in brain: metabolic mapping at the cellular level. Science, v. 240, p. 1328-1331, 1988.

SANDKUHLER, J. The organization and function of endogenous antinociceptive systems, Prog. Neurobiol., v. 50, p. 49-81, 1996.

SCHNITZLER, A.; PLONER, M. Neurophysiology and functional neuroanatomy of pain perception. J. Clin. Neurophysiol., v. 17, p. 592-603, 2000.

SENAPATI, A. K.; HUNTINGTON, P. J.; PENG, Y. B. Spinal dorsal horn neuron response to mechanical stimuli is decreased by electrical stimulation of the primary motor cortex. Brain Res., v. 1036, p. 173-179, 2005a.

SENAPATI, A. K.; LAGRAIZE, S. C.; HUNTINGTON, P. J.; WILSON, H. D.; FUCHS, P. $\mathrm{N}$.; PENG, Y. B. Electrical stimulation of the anterior cingulate cortex reduces responses of rat dorsal horn neurons to mechanical stimuli. J. Neurophysiol., v. 94, p. 845-851, 2005b.

SCHOLZ, J.; WOOLF, C. J. Can we conquer the pain? Nature Neuroscience Supplement, v. 5, p. 1062-1067, 2002.

STAMFORD, J. A. Descending control of pain. Br. J. Anaesth., v. 75, p. 217-227, 1995.

STUCKY, C. L; GOLD, M. S.; ZHANG, X. Mechanisms of pain. Proc. Natl. Acad. Sci. U S A, v. 98, p. 11845-11846, 2001. 
SUZUKI, R.; RAHMAN, W.; HUNT, S. P.; DICKENSON, A. H. Descending facilitatory control of mechanically evoked responses is enhanced in deep dorsal horn neurons following peripheral nerve injury. Brain Res., v. 1019, p. 68-76, 2004.

TAI, C.; ZHU, S.; ZHOU, N. TRPA1: The central molecule for chemical sensing in pain pathway. The Journal of Neuroscience, v. 28, p. 1019-1021, 2008.

TAO, R.; AUERBACH, S. B. Mu-opioids disinhibit and kappa-opioids inhibit serotonin efflux in the dorsal raphe nucleus. Brain Res., v. 1049, p. 70-79, 2005.

TRAFTON, J. A.; ABBADIE, C.; MARCHAND, S.; MANTYH, P. W.; BASBAUM, A. I. Spinal Opioid Analgesia: How Critical Is the Regulation of Substance P Signaling? J. Neurosc., v. 19, p. 9642-9653, 1999.

TSUBOKAWA, T.; KATAYAMA, Y.; YAMAMOTO, T.; HIRAYAMA, T.; KOYAMA, S. Chronic motor cortex stimulation in patients with thalamic pain. J. Neurosurg., v. 78, p. 393401, 1993.

TSUBOKAWA, T.; KATAYAMA, Y.; YAMAMOTO, T.; HIRAYAMA, T.; KAYAMA, S. Motor cortex stimulation for control of thalamic pain. Pain (Suppl.), v. 5, p. 491, 1990.

TSUBOKAWA, T.; KATAYAMA, Y.; YAMAMOTO, T.; HIRAYAMA, T.; KOYAMA, $\mathrm{S}$. Treatment of thalamic pain by chronic motor cortex stimulation. Pacing Clin. Electrophysiol., v.14, p. 131-134, 1991.

URBAN, M. O.; SMITH, D. J. Nuclei within the rostral ventromedial medulla mediating morphine antinociception from the periaqueductal gray. Brain Res., v. 652, p. 9-16, 1994.

VACULIN, S.; FRANEK, M.; YAMAMOTOVA, A.; ROKYTA, R. Motor cortex stimulation in rats with chronic constriction injury. Exp. Brain Res., v. 185, p. 331-335, 2008.

VANEGAS, H.; SCHAIBLE, H. G. Descending control of persistent pain: inhibitory or facilitatory? Brain Res Rev., v. 46, p. 295-309, 2004.

VIISANEN-KUOPILA, H. Descending modulation of pain by motor cortex stimulation in the rat. Efficacy and mechanisms in peripheral neuropathy. 2012. 105 p. Ph D. thesis Academic dissertation. Faculty of Medicine of the University of Helsinki. Helsinki, 2012.

VIISANEN, H.; PERTOVAARA, A. Antinociception by motor cortex stimulation in the neuropathic rat: does the locus coeruleus play a role? Exp. Brain Res., v. 201, p. 283-296, 2010a.

VIISANEN, H.; PERTOVAARA, A. Roles of the rostroventromedial medulla and the spinal 5-HT1Areceptor in descending antinociception induced by motor cortex stimulation in the neuropathic rat. Neurosc. Lett., v. 476, p. 133-137, 2010b.

WALLIN, J. SCHOTT, E. Substance P release in the spinal dorsal horn following peripheral nerve injury. Neuropeptides, v. 36, p. 252-256, 2002.

WANG, Q.; NAKAI, Y. The Dorsal Raphe: An Important Nucleus in Pain. Brain Res. Bull., v. 34, p. 575-585, 1994.

WELCH, S. P. Interaction of the cannabinoid and opioid systems in the modulation of nociception. Int. Rev. Psychiatry, v. 21, p. 143-151, 2009. 
WOOLF, C. J.; SALTER, M.W. Plasticity and pain: role of the dorsal horn. In: MCMAHON, S. B.; KOLTZENBURG, M. (Ed.). Wall and Melzack's Textbook of Pain. Philadelphia: Elsevier, 2006. p. 91-105.

XIE, Y.; HUO, F.; TANG, J. Cerebral cortex modulation of pain. Acta Pharmacol. Sin., v. 30, p. 31-41, 2009.

ZIMMERMANN, M. Ethical guidelines for investigations of experimental pain in conscious animals. Pain, v. 16, p. 109-110, 1983.

ZIMMER, M. B.; GOSHGARIAN, H. G. Spinal Activation of serotonin 1a receptors enhances latent respiratory activity after spinal cord injury. J. Spinal. Cord. Med., v. 29, p. 147-155, 2006.

ZORMAN, G.; BELCHER, G.; ADAMS, I. E.; FIELDS, H. L. Lumbar intrathecal naloxone blocks analgesia produced by microstimulation of the ventromedial medulla in the rat. Brain Res., v. 236, p. 77-84, 1982. 